ARTICLE

\title{
Toll-like receptor signaling in thymic epithelium controls monocyte-derived dendritic cell recruitment and Treg generation
}

\author{
Matouš Vobořil ${ }^{1}$, Tomáš Brabec ${ }^{1}$, Jan Dobeš (1) ${ }^{1}$, Iva Šplíchalová', Jiří Březina (1) ${ }^{1}$, Adéla Čepková1, \\ Martina Dobešová', Aigerim Aidarova1', Jan Kubovčiak², Oksana Tsyklauri, Ondřej Štěpánek (i) ${ }^{3}$, \\ Vladimír Beneš ${ }^{4}{ }^{4}$, Radislav Sedláček ${ }^{5}$, Ludger Klein ${ }^{6}$, Michal Kolář ${ }^{2}$ \& Dominik Filipp (iD) ${ }^{1 凶}$
}

The development of thymic regulatory $T$ cells (Treg) is mediated by Aire-regulated selfantigen presentation on medullary thymic epithelial cells (mTECs) and dendritic cells (DCs), but the cooperation between these cells is still poorly understood. Here we show that signaling through Toll-like receptors (TLR) expressed on mTECs regulates the production of specific chemokines and other genes associated with post-Aire mTEC development. Using single-cell RNA-sequencing, we identify a new thymic CD14 ${ }^{+}$Sirp $\alpha^{+}$population of monocytederived dendritic cells $\left(\mathrm{CD} 14^{+} \mathrm{moDC}\right)$ that are enriched in the thymic medulla and effectively acquire $\mathrm{mTEC}$-derived antigens in response to the above chemokines. Consistently, the cellularity of $\mathrm{CD}_{14}{ }^{+} \mathrm{moDC}$ is diminished in mice with MyD88-deficient TECs, in which the frequency and functionality of thymic $\mathrm{CD} 25^{+} \mathrm{Foxp} 3^{+}$Tregs are decreased, leading to aggravated mouse experimental colitis. Thus, our findings describe a TLR-dependent function of $\mathrm{mTECs}$ for the recruitment of $\mathrm{CD} 14^{+} \mathrm{moDC}$, the generation of Tregs, and thereby the establishment of central tolerance.

\footnotetext{
${ }^{1}$ Laboratory of Immunobiology, Institute of Molecular Genetics of the Czech Academy of Sciences, Prague, Czech Republic. ${ }^{2}$ Laboratory of Genomics and Bioinformatics, Institute of Molecular Genetics of the Czech Academy of Sciences, Prague, Czech Republic. ${ }^{3}$ Laboratory of Adaptive Immunity, Institute of Molecular Genetics of the Czech Academy of Sciences, Prague, Czech Republic. ${ }^{4}$ Genomics Core Facility, EMBL, Services \& Technology Unit, Heidelberg, Germany. ${ }^{5}$ Czech Centre for Phenogenomics \& Laboratory of Transgenic Models of Diseases, Institute of Molecular Genetics of the Czech Academy of Sciences, Prague, Czech Republic. ${ }^{6}$ Faculty of Medicine, Institute for Immunology, Ludwig-Maximilans-Universitat, Munich, Germany.

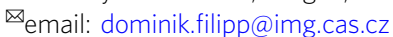


T he establishment of tolerance is a fundamental attribute of a healthy immune system. Since $\mathrm{T}$ cell antigen receptors (TCRs) are generated by random somatic recombination, i.e. could be self or nonself-specific, $\mathrm{T}$ cells that express a selfreactive TCR must be removed from the conventional $\mathrm{T}$ cell repertoire. The critical part of this process occurs in the thymic medulla where the strength of TCR recognition of self-antigens is probed by various types of antigen presenting cells (APCs), mainly dendritic cells (DCs), B-cells, and highly specialized medullary thymic epithelial cells (mTECs) ${ }^{1}$. mTECs mediate the promiscuous expression of thousands of otherwise strict tissuerestricted self-antigens (TRAs), a large number of which are under the control of the transcriptional regulator Aire $^{2}$. The presentation of TRAs by mTECs can result in either the deletion of self-reactive $\mathrm{T}$ cells ${ }^{3}$ or their conversion into Tregs ${ }^{4,5}$

It has been recently demonstrated that the process of cooperative antigen transfer (CAT) from mTECs to DCs is essential for the establishment of thymic tolerance ${ }^{6-11}$. The complexity of CAT is foremost due to the heterogeneity of DCs in the thymus. These $\mathrm{CD} 11 \mathrm{c}^{+}$cells are comprised of two major categories: $\mathrm{B}^{2} 20^{+}$plasmacytoid DCs (pDC) and classical DCs (cDCs), the latter which can be subdivided into $\mathrm{Xcr}{ }^{+}{ }^{+} \mathrm{CD} 8 \alpha^{+} \mathrm{Sirpa}^{-}$classical type $1 \mathrm{DCs}$ (cDC1) and $\mathrm{Xcr}^{-} \mathrm{CD} 8 \alpha^{-}$Sirpa ${ }^{+}$classical type $2 \mathrm{DCs}(\mathrm{cDC} 2)^{12,13}$. While $\mathrm{CDC1}$ arise primarily in the thymus, $\mathrm{CDC} 2$ and pDCs originate extrathymically and then migrate to the thymic medullary region ${ }^{14,15}$. mTEC-derived antigens are transferred both to thymic resident $\mathrm{CDC1} 1^{6,10}$ and $\mathrm{CDC} 2^{16,17}$. Although it has been shown that the migration of $\mathrm{cDCl}$ and $\mathrm{CDC} 2$ to the vicinity of mTECs is affected by a gradient of $\mathrm{Xcl}^{18}$ and $\mathrm{Ccr} 2 / \mathrm{Ccr} 7$ ligands, respectively ${ }^{19,20}$, the potential involvement of other chemokines in the regulation of CAT still awaits resolution.

Toll-like receptors (TLRs) sense various immunologically relevant microbial ligands such as lipoproteins, carbohydrates, and nucleic acids. All TLRs, with the exception of TLR3, signal through the adaptor protein, MyD88, which via the activation of the NF- $\mathrm{kB}$ pathway induces the expression of pro-inflammatory cytokines, chemokines, and other inflammation-related molecules ${ }^{21}$. While the exact role of non-canonical NF- $\mathrm{kB}$ signaling in the development and function of mTECs has been previously demonstrated ${ }^{22-24}$, the impact of TLR signaling via the canonical NF- $\mathrm{kB}$ pathway in the physiology of mTECs remains undetermined.

Here, we show that, among TLRs, mTECs abundantly express TLR9, and the stimulation of which leads to the influx of Xcr1 ${ }^{-}$ $\mathrm{Sirpa}^{+}$cDC2 into the thymic medulla. RNA sequencing of stimulated mTECs reveals that the mechanism underpinning this phenomenon is related to the upregulation of a set of chemokines, whose receptors are predominantly expressed by a $\mathrm{CD} 14^{+}$subset of thymic DCs, which have been identified as monocyte-derived DCs $\left(\mathrm{CD} 14^{+}\right.$moDC). Furthermore, mice with MyD88-deficient TECs, which exhibit a deficiency in the recruitment of CD14 ${ }^{+}$ moDC, also suffer from a decreased thymic Treg output and functionality, which renders the peripheral $\mathrm{T}$ cell repertoire prone to colitis induction.

\section{Results}

mTECs express a set of TLRs and signaling adaptors. The function of TLR signaling in the physiology of mTECs has not yet been studied in detail ${ }^{25-27}$. We first determined that both mTECs $^{\text {low }}$ and mTECs high subsets (Fig. 1a and Supplementary Fig. 1a) expressed TLR2, 3, 4, and 9 (Fig. 1b). Remarkably, TLR9, which recognizes bacterial, viral or altered $\mathrm{DNA}^{21}$ and ligands associated with cellular stress ${ }^{28}$, is highly expressed by mTECs ${ }^{\text {high }}$ at levels comparable to thymic cDCs (Fig. 1a, b and Supplementary Fig. 1b). Transcripts of TLR adaptors MyD 88 and Trif 21 were also readily detectable (Fig. 1c). Although the levels of TLR4 and TLR9 were higher in mTECs ${ }^{\text {high }}$, the major producers of Aire, our analysis of Aire ${ }^{+/+}$and Aire ${ }^{-/}$mice revealed that TLRs are expressed in an Aire-independent manner (Fig. 1d).

To assess the significance of TLR/MyD88 signaling in TECs development, we crossed a thymic epithelial cell-specific Foxn1 ${ }^{\text {Cre }}$ driver $^{29}$ with a MyD88 $8^{\mathrm{fl} / \mathrm{fl}}$ transgenic mice ${ }^{30}$ (hereafter called MyD88 $\left.{ }^{\triangle T E C}\right)$. In comparison to the control, MyD88 ${ }^{\Delta T E C s}$ mice showed no significant differences in the frequency of all tested TEC subpopulations (Fig. 1e, f), suggesting that canonical NF- $\mathrm{kB}$ signaling through TLRs/MyD88 does not affect mTEC $^{\text {high }}$ maturation. Similarly, in all mTEChigh subsets, the expression of CD80, CD86, PD-L1, CD40, and ICOSL on was not altered (Supplementary Fig. 1c).

Together, this data demonstrates that TLRs are broadly expressed by mTECs and MyD88-dependent signaling has no apparent impact on TEC subpopulation frequency.

MyD88-dependent chemokine expression in mTECs ${ }^{\text {high }}$. Given the high expression of selected TLRs in mTECshigh cells, we assessed the impact of the absence of TLR signaling in unperturbed conditions. RNA-sequencing of mTECs ${ }^{\text {high }}$ (sorted as shown in Supplementary Fig. 1a) from wild type $\left(\mathrm{MyD}^{\mathrm{ft} / \mathrm{fl}}\right)$ and MyD88 ${ }^{\triangle T E C s}$ mice revealed MyD88-dependent transcriptional variance (Fig. 2a) defined by 303 differentially expressed transcripts (Fig. 2b and Supplementary Data 1 and 2). While 206 of these transcripts were induced and 97 repressed by MyD88, they were not enriched for Aire-dependent or Aire-independent TRA genes $^{31}$ (Supplementary Fig. 2a, left panel). Consistent with the role of TLR/MyD88 signaling in epithelial cells ${ }^{21}$, we found several differentially expressed genes (DEGs) which fell into one of two categories: (i) Illff6 and Csf2 cytokines, (ii) Ccl25, Ccl4, and Ccl24 chemokines. These mediators act through receptors that are primarily expressed by myeloid cells and DCs ${ }^{32}$. Specifically, IL36R, the receptor for IL1F6, is expressed by DCs and T cells ${ }^{33}$ while Csf2r, the receptor for Csf2, is expressed mostly by monocytes, macrophages, and granulocytes ${ }^{34}$. The Ccr9, the receptor for Ccl25, is expressed by both thymocytes and pDCs driving their migration into the thymus ${ }^{14,35}$. Both Ccr5 (receptor for Ccl4) and Ccr3 (receptor for Ccl24) are expressed predominantly on granulocytes and DCs modulating their migration into inflamed tissues 32,36 . qRT-PCR analysis confirmed MyD88-regulated expression of selected genes in mTECs ${ }^{\text {high }}$ (Fig. 2c). Since the TLRs were postulated to sense both microbial and endogenous molecule ${ }^{21}$, we examined which of them could potentially act as a trigger. The analysis of mRNA expression of MyD88-dependent cytokines and chemokines (Fig. 2b, c) in the mTEChigh population isolated from either Germ-free (GF) or specific-pathogen-free (SPF) mice was comparable (Supplementary Fig. 2b), indicating that these signals are likely of endogenous origin.

Next, we assessed the response of mTECs to TLR/ MyD88 stimulation. Given the high expression of TLR9 (Fig. 1b), we stimulated mTECs $s^{\text {high }}$ from MyD88-deficient $\left(\mathrm{MyD}^{2} 8^{-I-}\right)$ and WT $\left(\mathrm{MyD} 8^{+/+}\right)$mice in vitro with $\mathrm{CpG}$ oligodeoxynucleotides (CpG ODN) or PBS. RNA-sequencing revealed significant changes in the transcriptional profile only in $\mathrm{MyD}^{+} 8^{+/+}$cells. Notably, 347 DEGs were associated with TLR9 stimulation (Fig. 2d, e and Supplementary Data 3 and 4), and of these, 198 were upregulated while 149 were downregulated. However, the pattern of expression of TRA genes remained largely unchanged after in vitro CpG ODN stimulation (Supplementary Fig. 2a, right panel). Importantly, among the most upregulated DEGs were two sets of chemokines: (i) Cxcl1, 2, 3, and 5, which signal via the Cxcr2 receptor, expressed predominantly on neutrophils ${ }^{37}$ and (ii) $\mathrm{Ccl} 3,5$ and 20 which signal via various chemokine receptors, including Ccr1, 3, 5, 6 which are expressed mostly on myeloid 
a

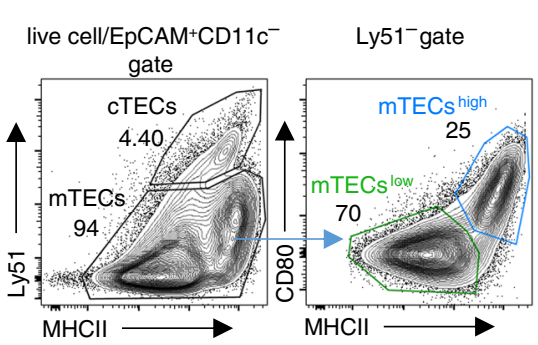

MACS CD $45^{+}$

live/singlets gate

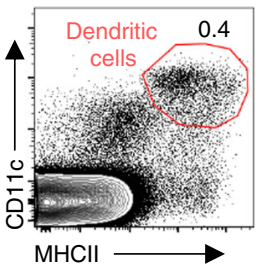

b
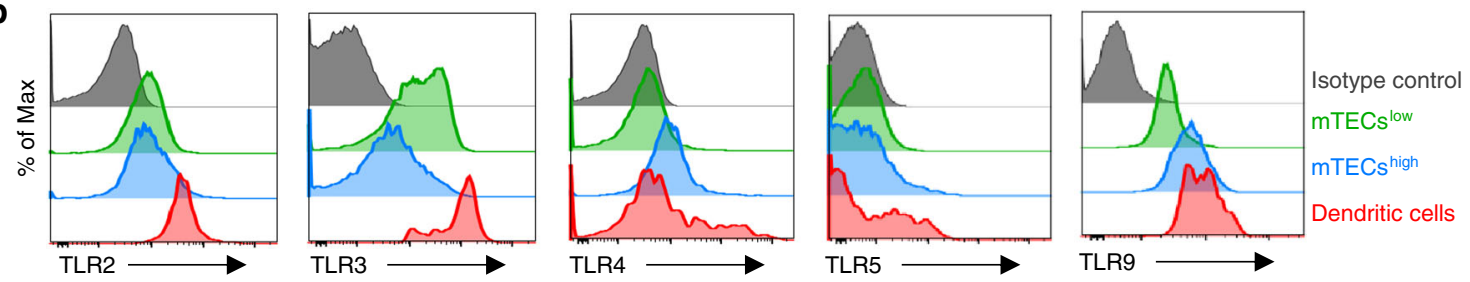

C
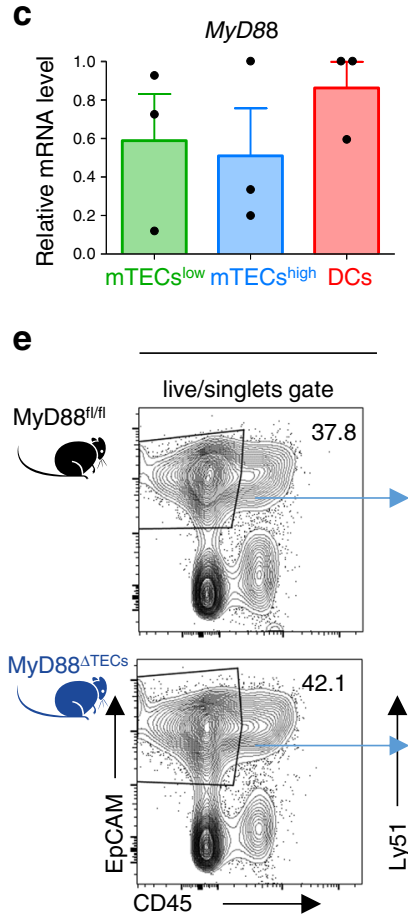

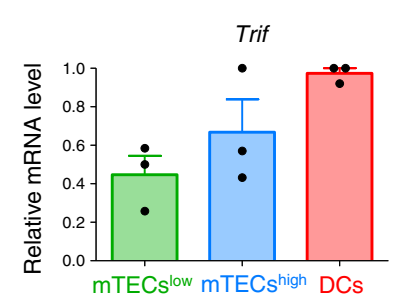

MACS CD45$\mathrm{EpCAM}^{+} \mathrm{CD} 45^{-}$gate
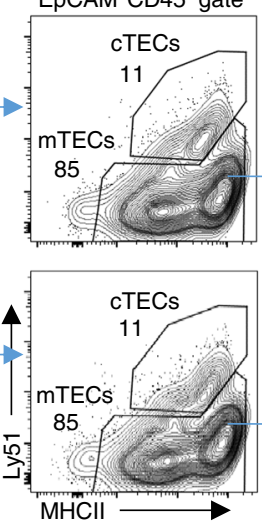
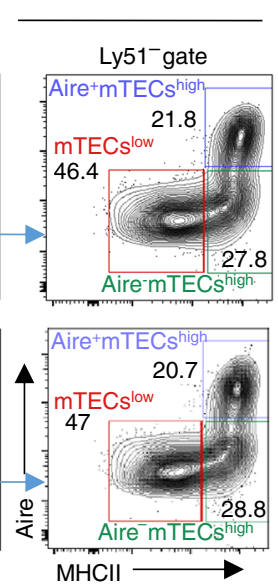

d
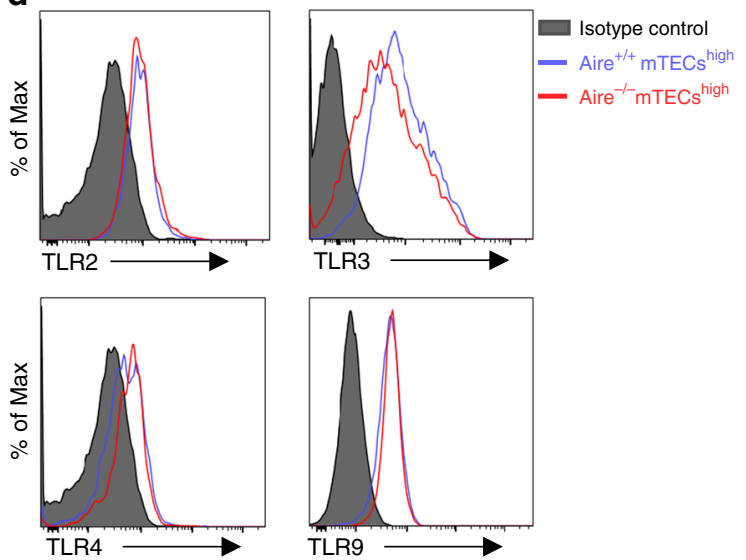

f

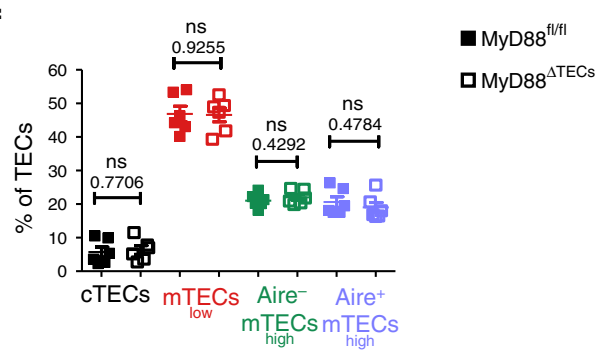

Fig. 1 mTECs express a set of TLRs and their signaling adaptors independently of Aire. a Gating strategy used for the analysis of TEC populations and general thymic conventional DCs. MACS enriched CD45- and EpCAM ${ }^{+}$CD11c ${ }^{-}$pre-gated cells were further divided into cTECs $\left(\right.$Ly51 $\left.{ }^{+}\right)$, mTECs low

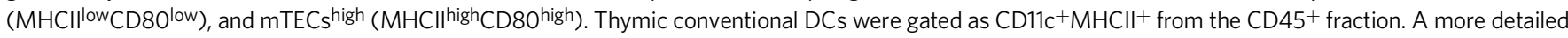
gating strategy is found in Supplementary Fig. 1a, b. b Representative flow cytometry histograms of TLR expression on mTECs and DCs isolated from the thymus ( $n=3$ independent experiments). c MyD88 and Trif mRNA expression is determined by qRT-PCR from FACS sorted mTECs and DCs. The expression is calculated relative to Casc3 and normalized to the highest value within each experiment $=1$ (mean \pm SEM, $n=3$ samples). d Representative flow cytometry histograms of TLR expression on mTECs from Aire ${ }^{+/+}$and Aire ${ }^{-/-}$mice, $(n=3$ independent experiments). e Representative comparative flow cytometry plots

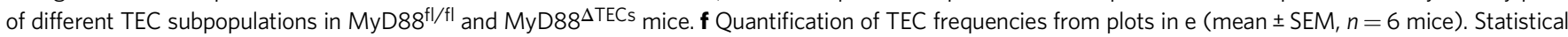
analysis was performed by unpaired, two-tailed Student's t-test, p-values are shown. ns = not significant.

cells $^{32}$. Cytokines (Tnfo, Il-6, Il12a, Il1f6 and Csf2) and other genes $(C d 40)$ were also found to be upregulated (Fig. 2e). The upregulation of $\mathrm{Cxcl} 1$ and $\mathrm{Ccl} 5$ chemokines after in vitro (Fig. 2f) as well as in vivo intrathymic TLR9 stimulation (Fig. $2 \mathrm{~g}$ ) was confirmed by qRT-PCR analysis. As shown in Supplementary Fig. 2c, repeated intraperitoneal (i.p.) injection of $\mathrm{CpG}$ ODN was insufficient for the upregulation of chemokines in mTECs high. It is of note that in vitro stimulation of TLR 4 on mTECs ${ }^{\text {high }}$ by LPS also resulted in the upregulation of the previously noted chemokines, albeit at a lower level (Supplementary Fig. 2d).

In addition to TLRs, MyD88 also conveys signals generated by IL-1 family cytokines, such as IL- $1 \beta$, IL-18 or IL-33 ${ }^{38}$. Even though the receptors for these cytokines are expressed by mTECshigh (Supplementary Fig. 3a), only in vitro stimulation with IL-1 $\beta$ lead to the upregulation of cytokines and chemokines induced by TLR9 stimulation (Supplementary Fig. 3b). 
a

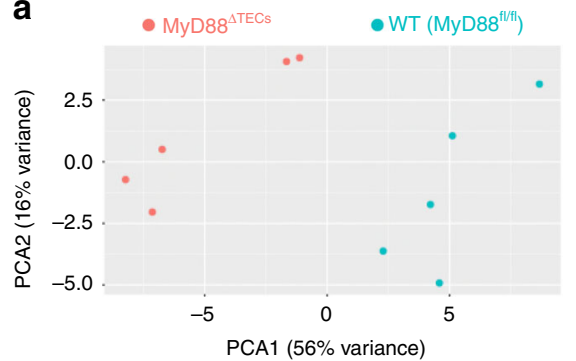

C
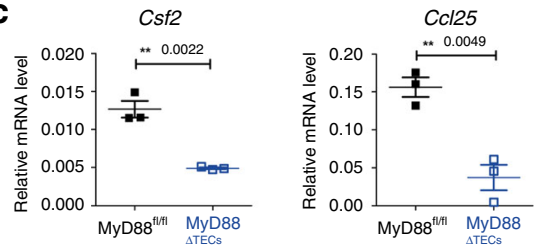

d
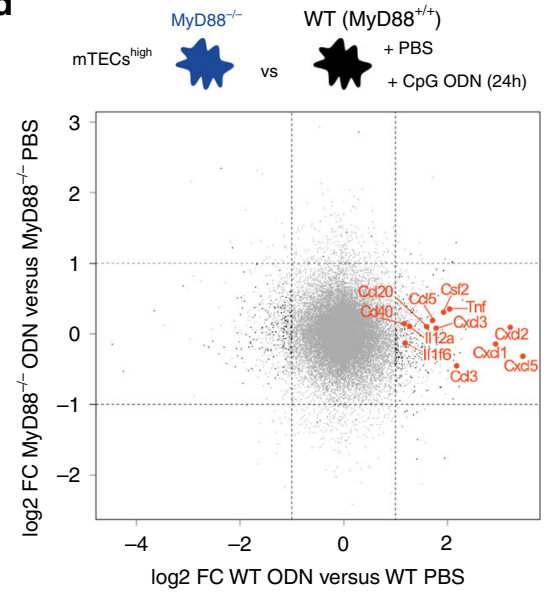

f

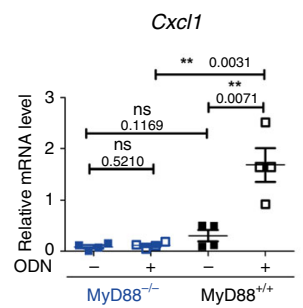

b

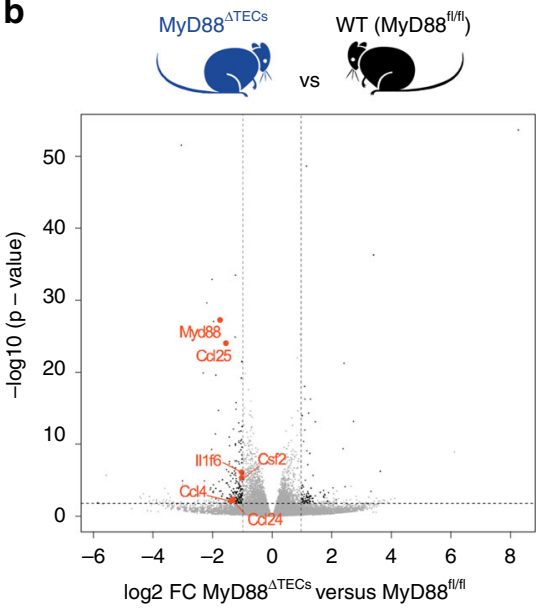

e

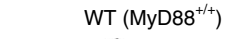

mTECs ${ }^{\text {high }}$

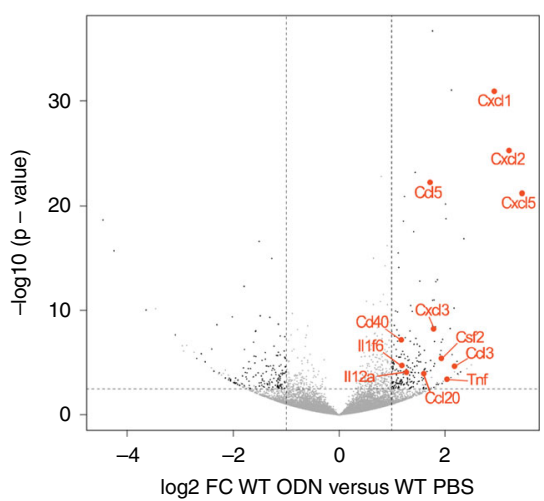

g $W T(C 57 B \mathrm{~B} / 6 \mathrm{~J})$

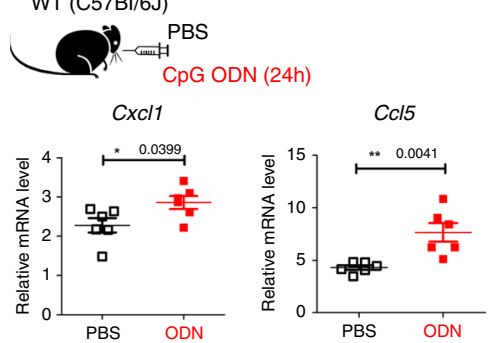

Fig. 2 TLR/MyD88 signaling in mTECs $^{\text {high }}$ drives the expression of cytokines and chemokines. a Principal component analysis of bulk RNA-sequencing data from mTECs ${ }^{\text {high }}$ (sorted as in Supplementary Fig. 1a) derived from MyD88 $8^{f l / f l}$ and MyD88 $8^{\Delta T E C s}$ mice. Data represents the analysis of $n=5$ samples for each condition. $\mathbf{b}$ Volcano plot analysis of RNA-sequencing data described in $\mathbf{a}$. Fold-change cutoff of log $2= \pm 1,0$ and $p$-value: 0.05 are marked by dashed lines (also in d, e). Differentially expressed genes are depicted in black, genes of interest are in red, and other detected genes in grey. $\mathbf{c}$ qRT-PCR analysis of relative mRNA expression normalized to Casc3 of genes selected from $b$ (mean \pm SEM,$n=3$ samples). $\mathbf{d}$ Fold-change fold-change plot of RNAsequencing data from CpG ODN or PBS in vitro stimulated mTECs high (sorted as in Supplementary Fig. 1a) from MyD88 $8^{+/+}$and MyD88 $8^{-/-}$mice $(n=$ 4 samples for each condition). Color code as in $\mathbf{b}$. e Volcano plot analysis of RNA-sequencing data from d, comparing CpG ODN versus PBS in vitro stimulated mTECs ${ }^{\text {high }}$ from MyD88 $+/+$ mice. Statistical analysis for $b, d$ and e was performed by Wald test, $p$-value cutoff: 0.05 . f, $\mathbf{g}$ qRT-PCR analysis of Cxcl1 and Ccl5 mRNA expression (normalized to Cacs3) from in vitro (mean \pm SEM, $n=4$ samples) and intrathymically (mean \pm SEM, $n=6$ mice), respectively, CPG ODN or PBS stimulated mTECs high from indicated animals. Statistical analysis for $\mathbf{c}, \mathbf{f}$, and $\mathbf{g}$ was performed by unpaired, two-tailed Student's t-test, $p \leq 0.05={ }^{\star}, p \leq 0.01={ }^{\star \star}$, ns not significant.

Besides chemokines and cytokines, TLR/MyD88 signaling in mTECs ${ }^{\text {high }}$ (Fig. 2b) also regulated the expression of molecules associated with cornified epithelial pathway ${ }^{39}$ (Supplementary Data 1-4). This specifically relates to genes that are associated with post-Aire mTECs ${ }^{40,41}$, such as Krt10, Krt77 and Flg2 (Supplementary
Fig. 3c). Moreover, previously published data has shown the enhanced expression of Illf6, Cxcl3 and Cxcl5 in post-Aire mTECs ${ }^{42}$. Thus, we enumerated the total numbers of Involucrin ${ }^{+} \mathrm{EpCAM}^{+}$ cells in the medullary region of the CPG ODN intrathymically stimulated thymus. We did not observe any changes in the frequency 
of general mTECs subsets (Supplementary Fig. 3d) although the total numbers of Involucrin ${ }^{+}$post-Aire mTECs were significantly increased (Supplementary Fig. 3e, f).

Together, these results show that TLR/MyD88 signaling in mTECs under physiological or stimulatory conditions regulates the differentiation of mTEChigh cells into Involucrin ${ }^{+}$post-Aire stage. This stage is associated with the expression of a set of chemokines that signal via an overlapping set of chemokine receptors that are primarily expressed by DCs ${ }^{32}$.

TLR9/MyD88 signaling in mTECs targets Sirpa ${ }^{+}$cDC2. Migration of different DC subsets into the thymus is orchestrated by distinct chemokines ${ }^{14,18,19}$. Thus, we next assessed which of these subsets would be the target for TLR9/MyD88-induced chemokines in TECs. We sorted three main subsets of CD11c ${ }^{+} \mathrm{MHCII}^{+}$thymic DCs: $\mathrm{B}_{22}{ }^{+} \mathrm{pDC}, \mathrm{Sirpa}^{-} \mathrm{Xcr} 1^{+} \mathrm{cDC1}$, and Sirpa ${ }^{+} \mathrm{Xcr1}^{-} \mathrm{cDC} 2$ (Supplementary Fig. 4a), along with Gr-1 $1^{+}$granulocytes, CD4 and CD8 single positive thymocytes and performed qRT-PCR analysis of the chemokine receptors indicated above. Remarkably, apart from granulocytes, the chemokine receptors $\mathrm{Cxcr2}, \mathrm{Ccr} 1,3,5$, and 6 were mostly expressed by DCs, specifically by $\mathrm{CDC} 2$ and pDC (Fig. 3a). This prompted us to quantify the relative frequencies of all thymic DC subsets in MyD88 ${ }^{\Delta \mathrm{TECs}}$ in comparison to WT (MyD88 $\left.8^{\mathrm{fl} / \mathrm{fl}}\right)$ mice. In unstimulated conditions, TEC-intrinsic MyD88 signaling did not change the total frequency of $\mathrm{CD}_{11 \mathrm{c}^{+}} \mathrm{MHCII}^{+} \mathrm{DCs}$ (Fig. 3b, left plot). However, we observed alterations in the frequencies of DC subsets. While $\mathrm{CDC1}$ were increased, the frequencies of $\mathrm{pDC}$ and $\mathrm{CDC} 2$ were diminished in the MyD88 ${ }^{\triangle \mathrm{TECs}}$ thymus (Fig. 3b). In contrast, FACS analysis of TLR9-stimulated thymi revealed a significant increase in $\mathrm{CDC} 2$ accompanied by decreased cDC1 in the thymus of WT (MyD88 $8^{\mathrm{l} / \mathrm{fl}}$ ) (Fig. 3c and Supplementary Fig. $4 \mathrm{~b}, \mathrm{c}$ ) but not MyD88 ${ }^{\triangle \mathrm{TECS}}$ animals (Fig. $3 \mathrm{c}$ ). The frequencies of pDC remained comparable under these two conditions. This demonstrates that the recruitment of $\mathrm{CDC} 2$ to the thymus is attributable specifically to TLR9 signaling in TECs (Fig. 3c and Supplementary Fig. $4 \mathrm{~b}$ ). In agreement with medullary localization of cDC2 (Supplementary Fig. 4d), microscopically examined thymi from WT mice stimulated with CpG ODN showed an enrichment of $\mathrm{CD} 11 \mathrm{c}^{+} \mathrm{Sirp}^{+} \mathrm{CDC} 2$ exclusively in the keratin14-rich medullary region (Figs. 3d, e).

Together, this data suggests that MyD88-driven chemokines expressed by mTECs ${ }^{\text {high }}$, target receptors on thymic Sirpa ${ }^{+}$cDC2 and mediate their recruitment to the thymic medulla in steady state and TLR9 stimulatory conditions.

TLR9/MyD88 signaling in mTECs recruits $\mathrm{CD}^{+}{ }^{+}$moDCs. Chemokine-dependent migration of DCs to the proximity of mTECs, which underpins the mechanisms of CAT ${ }^{18}$, has been shown to be essential for the presentation of MTEC-derived antigens by $\mathrm{DCs}^{6,10}$. One prediction from the TEC-dependent TLR/MyD88-induced influx of Sirpa ${ }^{+} \mathrm{CDC} 2$ to the thymic medulla is that the frequency of CAT to this subset would be enhanced.

To verify this prediction, we crossed Foxn1Cre mice with ROSA26 TdTOMATO leading to TEC-specific, cytoplasmic expression of TdTOMATO (TdTOM) protein in the thymus. In agreement with a previous study ${ }^{9}$ and as shown in Supplementary Fig. 5a, we found two major populations of $\mathrm{TdTOM}^{+}$cells: (i) a $\mathrm{TdTOM}^{\text {high }} \mathrm{EpCAM}^{+}$population which was $\mathrm{CD}^{-} 5^{-}$and represented TECs expressing TdTOM endogenously (Supplementary Fig. 5b); and (ii) a $\mathrm{CD}^{+} 5^{+} \mathrm{TdTOM}^{+}$population comprised of mainly CD11c ${ }^{+}$DCs (Supplementary Fig. 5a) which acquired TdTOM via CAT (Fig. 4a). Interestingly, these DCs were enriched for the $\mathrm{EpCAM}^{+}$marker (Fig. 4b) which was likely co-transferred with $\mathrm{TdTOM}^{9}$. Bone marrow (BM) chimeras of lethally irradiated Foxn1 ${ }^{\text {Cre }}$ ROSA26 $6^{\text {TdTOMATO }}$ mice reconstituted with WT BM cells showed that around $6 \%$ of donor-derived DCs acquired TdTOM (Supplementary Fig. 5c-e). This formally demonstrates that TdTOM is transferred from TECs to DCs.

It has been previously documented that distinct subtypes of thymic DCs vary in their capacity to acquire antigens from TECs $s^{6,10,11,16}$. Whereas CAT of TdTOM from TECs to $\mathrm{CDC} 1$ and cDC2 is very potent in the Foxn 1 CreROSA26 TdTOMATO system, it is limited in the case of $\mathrm{pDC}$ (Fig. 4e, f). This result was also corroborated with the use of BM chimeras which were described above (Supplementary Fig. 5f). Flow cytometry imaging showed that transferred TdTOM in $\mathrm{MHCII}^{+} \mathrm{CD} 11 \mathrm{c}^{+}$DCs is localized intracellularly (Fig. $4 \mathrm{~g}$ ).

To determine the heterogeneity of all thymic DC subsets that participate in CAT, we performed single-cell RNA-sequencing $(\text { ddSEQ })^{43}$ of $\mathrm{Gr}-1^{-} \mathrm{CD} 11 \mathrm{c}^{+} \mathrm{TdTOM}^{+}$cells isolated from thymi of Foxn1 ${ }^{\text {Cre ROSA26 }} 6^{\text {TdTOMATO }}$ mice. Two-dimensional tSNE projection clustering analysis revealed five different clusters of $\mathrm{TdTOM}^{+}$ DCs (Fig. 5a). Based on their expression profiles and previously described signature genes of cells from mononuclear phagocyte system (MPS $)^{44}$, we designated the clusters in accordance with MPS nomenclature ${ }^{13}$ : two $\mathrm{cDCl}$ clusters (Batf3): a $\mathrm{cDCla}(\mathrm{Ccl} 5$ and $C c r 7)$ and $\mathrm{cDClb}(\mathrm{Cd} 8 \mathrm{a} \text {, Itgae, Xcr1 and Ppt1 })^{45}$; $\mathrm{cDC} 2$ cluster (Sirpo, Mgl2 and Cd209a) ${ }^{12}$, moDC cluster (Sirpo, Cd14, Itgam, Cx3cr1 and $C c r 2)^{46}$; and one pDC cluster (Bst2, Ccr9, Siglech, and Ly6d) ${ }^{14}$ (Fig. 5b and Supplementary Data 5). This data allowed the clustering of DCs which participate in CAT according to their specific surface markers (Supplementary Fig. 6a). As shown in Fig. 5b, the previously defined thymic moDC subpopulation shared several markers with both cDCs (Itgax, Itgam, Sirpa, and Irf4) and classical tissue resident macrophages (Lyz2, Mertk, and Mafb). Due to the high mRNA expression of molecules associated with antigen processing and presentation by moDC subpopulation (Supplementary Fig. $6 \mathrm{~b}$ ), we tested their capacity to present mTEC-derived antigens and activate antigen specific $\mathrm{T}$ cells. Specifically, thymic $\mathrm{CD} 14^{+}$moDCs isolated from the Aire-HCO mouse model expressing influenza hemagglutinin (HA) under the control of Aire regulatory sequences ${ }^{47}$, were co-cultivated with HA-specific $\mathrm{CD}^{+}$T cell hybridoma cells (A5) carrying a GFP-NFAT reporter ${ }^{4}$. While the result demonstrated that thymic $\mathrm{CD} 14^{+}$moDCs can efficiently present mTEC-derived antigens to T cells (Supplementary Fig. 6c), it seems that their previous detection was obstructed by using the previously established gating strategy (Supplementary Fig. 4a), by which they are indistinguishable from a conventional $\mathrm{Sirpa}^{+} \mathrm{CDC} 2$ subset.

Next, we determined which of the five defined thymic DC clusters expressed the receptors for TLR9/MyD88-induced chemokines/cytokines from mTECs (Figs. 2b, d, e). The heat map analysis of chemokine receptors identified by ddSEQ analysis revealed that most of these receptors were expressed by the Sirpa ${ }^{+} \mathrm{CD} 14^{+} \mathrm{moDC}$ cluster (Fig. $5 \mathrm{c}$, left panel). Interestingly, each of the $\mathrm{TdTOM}^{+}$DC clusters expressed a specific set of chemokine receptors (Fig. 5c).

Having characterized the CAT system with participating subsets of DCs in Foxn1 Cre ROSA26TdTOMATO mice, we used it as a readout to determine the targeting specificity of TEC-dependent TLR9/ MyD88 stimulation on these DC subsets. First, in general, TLR9 intrathymic stimulation of Foxn1 CreROSA26 TdTOMATO mice boosted the frequency of total TdTOM ${ }^{+} \mathrm{CD}_{11 \mathrm{c}^{+}}$DCs (Fig. 5d left graph and Supplementary Fig. 6d) as well as the mean fluorescent intensity (MFI) of TdTOM in these cells, demonstrating their enhanced rate of CAT under stimulatory conditions (Supplementary Fig. 6e). Second, as predicted, the observed increase in CAT was fully attributable to $\mathrm{TdTOM}^{+} \mathrm{Sirpa}^{+}$DCs and not to other DCs populations (Fig. 5d right graph and Supplementary Fig. 6f). Third, and most importantly, the unsupervised flow cytometry tSNE 

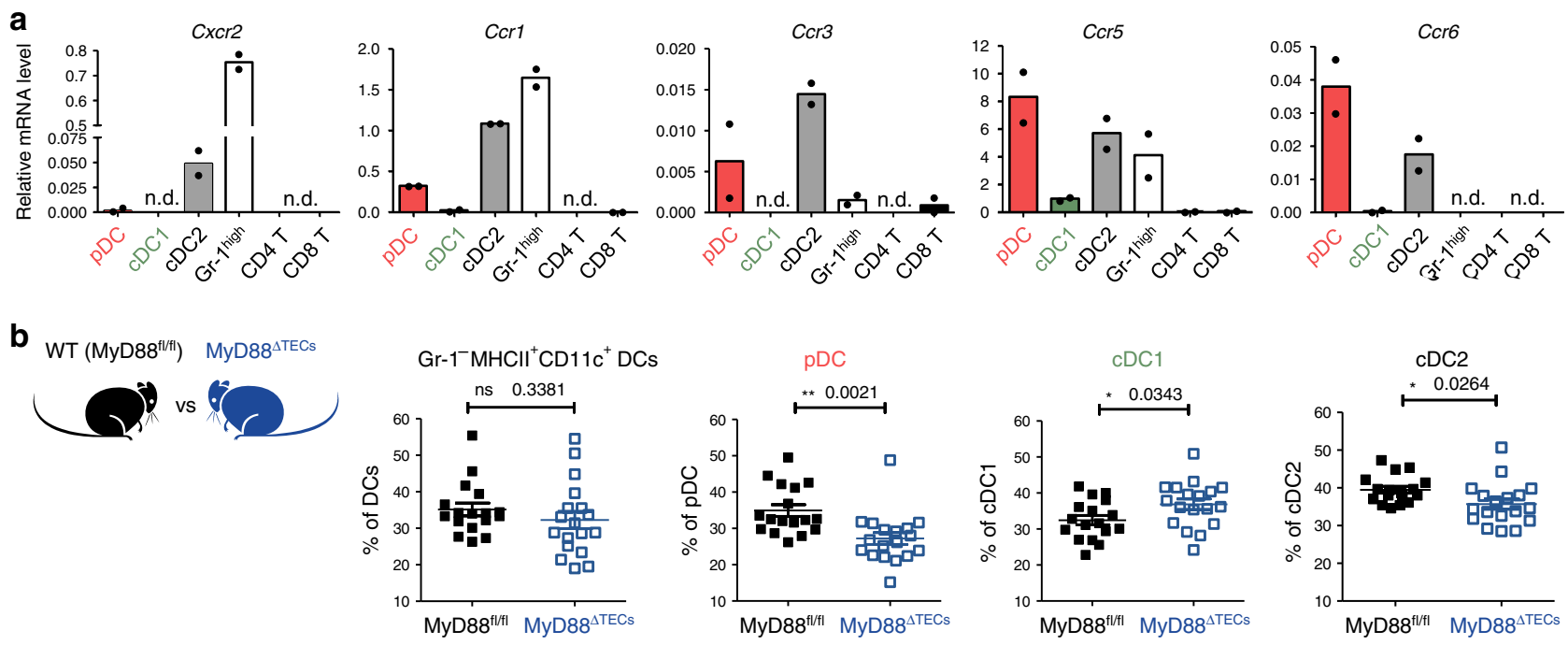

C
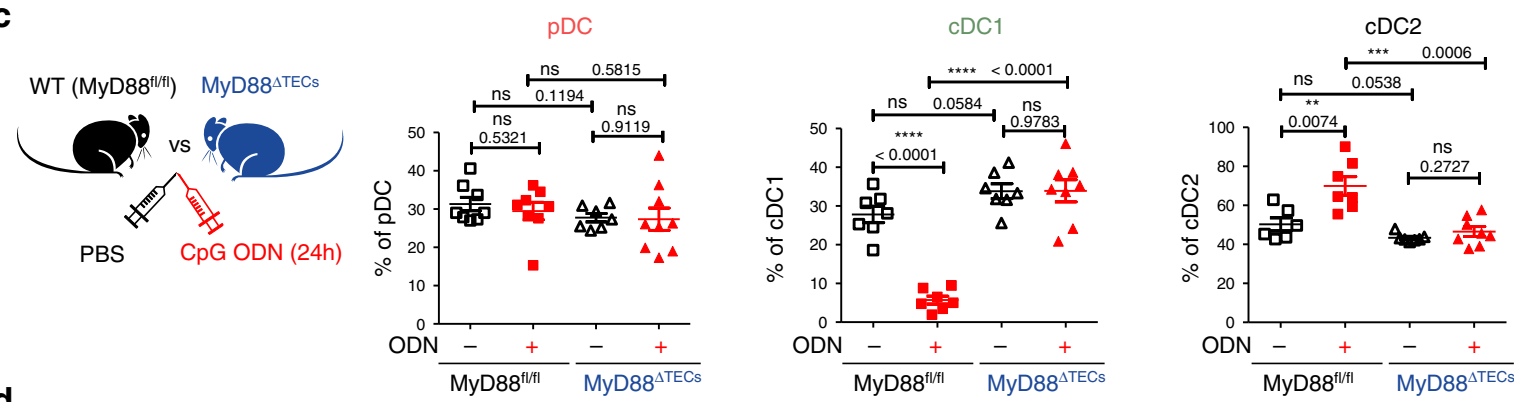

d $\quad$ WT $(\mathrm{C} 57 \mathrm{~B} \mathrm{~B} / 6 \mathrm{~J})$

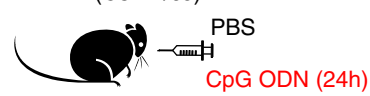
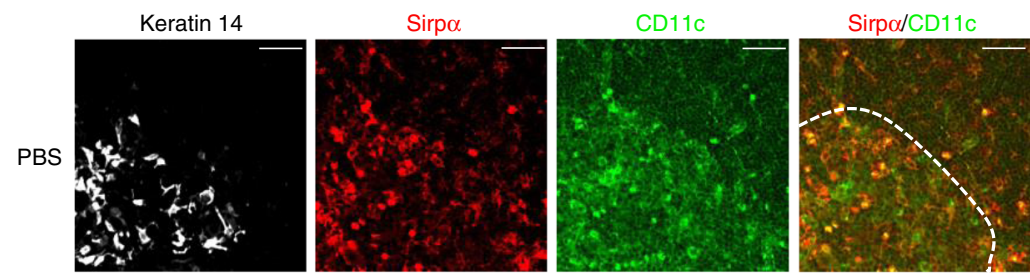

e Medullary region
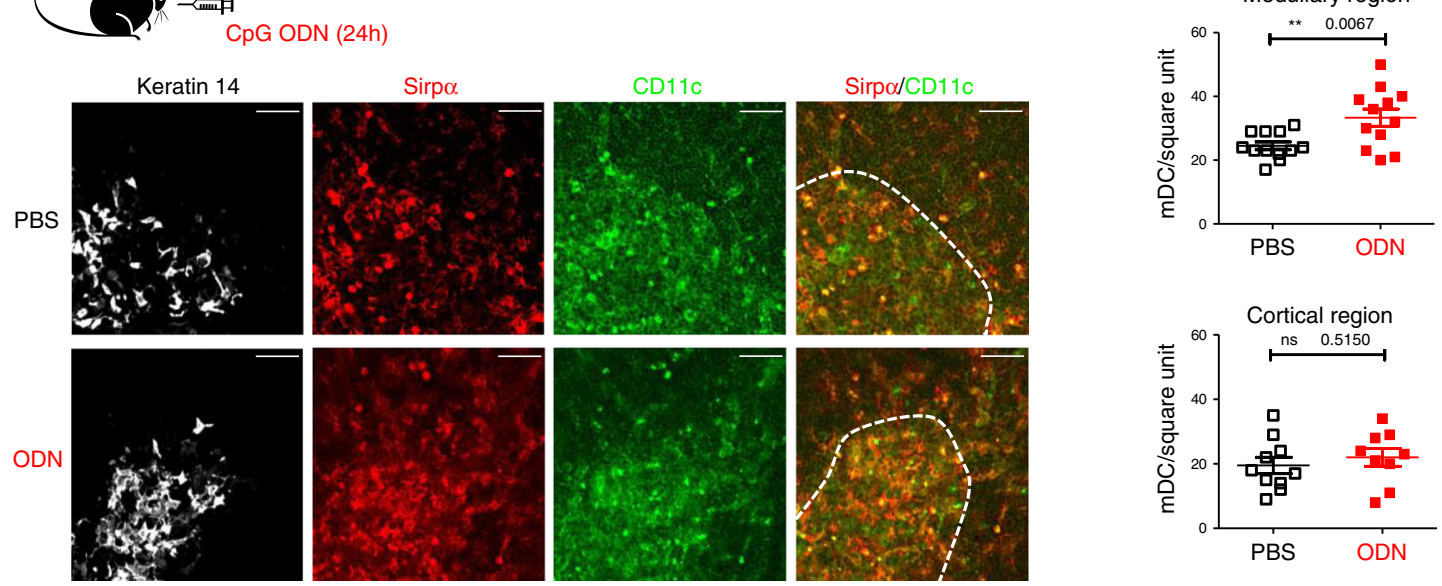

Fig. 3 TLR/MyD88 signaling in mTECs $^{\text {high }}$ affects the migration of DCs into the thymic medulla. a qRT-PCR analysis of the relative mRNA expression (normalized to Casc3) of indicated chemokine receptors on FACS sorted populations of thymic DCs; pDC plasmacytoid DCs, cDC1 classical type 1 DC, $\mathrm{cDC} 2$ classical type $2 \mathrm{DC}, \mathrm{Gr}-1^{\text {high }}=$ neutrophils, $\mathrm{CD} 4 \mathrm{~T}=\mathrm{CD} 4^{+}$, and $\mathrm{CD} 8 \mathrm{~T}=\mathrm{CD} 8^{+}$thymic $\mathrm{T}$ cells. Sorting protocol of thymic $\mathrm{DC}$ subsets is provided in Supplementary Fig. 4a. T cells were sorted as TCR $\beta^{+}$and either CD4 or CD8 single positive $(n=2$ independent experiments). $\mathbf{b}$ Comparative flow cytometry analysis of total DCs $\left(\mathrm{Gr}-1^{-} \mathrm{CD} 11 \mathrm{c}^{+} \mathrm{MHCll}{ }^{+}\right)$and different thymic $\mathrm{DC}$ subpopulations between MyD8 $8^{\mathrm{fl} / \mathrm{fl}}$ and $\mathrm{MyD} 88^{\Delta \mathrm{TECs}}$ mice enumerated according to gating strategy shown in Supplementary Fig. $4 a$ (mean $\pm \mathrm{SEM}, n=17$ for MyD8 $8^{\mathrm{fl} / \mathrm{fl}}$ and $n=18$ for MyD88 $8^{\Delta \mathrm{TECs}}$ mice). c Flow cytometry analysis of different thymic DC populations (gated as in Supplementary Fig. 4a) isolated from CpG ODN or PBS intrathymically stimulated MyD88fl/fl or

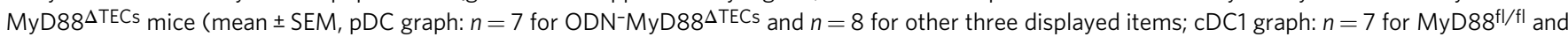

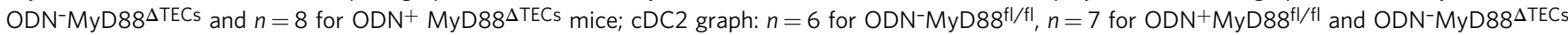
and $n=8$ for $\mathrm{ODN}^{+}$MyD88 ${ }^{\Delta \mathrm{TECs}}$ mice). Statistical analysis in $\mathbf{b}, \mathbf{c}$ was performed by unpaired, two-tailed Student's $t$-test, $p \leq 0.05={ }^{*}, p \leq 0.01={ }^{\star \star}, p \leq$ $0.001^{\star \star \star}, p<0.0001={ }^{\star \star \star \star}$, ns not significant. $\mathbf{d}$ Microscopic examinations of thymic sections isolated from CpG ODN or PBS intrathymically stimulated WT mice. Cryosections were stained with keratin 14 (white), Sirp $\alpha$ (red), and CD11c (green). Scale bar represents $50 \mu \mathrm{m}$. The white dashed line demarks keratin 14-rich medulla. e Quantification of $\mathrm{CD}_{11} \mathrm{c}^{+} \mathrm{Sirp} \alpha^{+}$cells in the medullar or cortical region of the cryosections shown in $d$ (mean \pm SEM, $n=12$ counted square unites per medullary region; $n=10$ and $n=9$ counted square unites per PBS- and ODN-treated cortical region, respectively. Data are derived from three independent experiments). Statistical analysis was performed by unpaired, two-tailed Student's $t$-test, $p \leq 0.01={ }^{\star \star}, \mathrm{ns}$ not significant. 
a

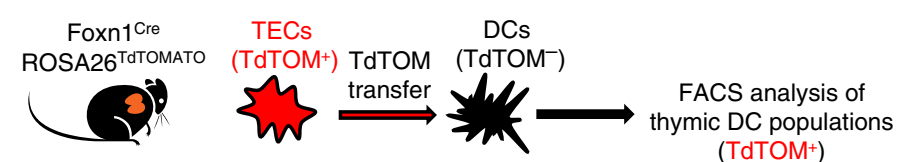

(TdTOM ${ }^{+}$) b

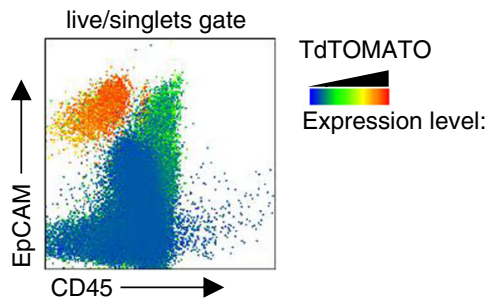

C

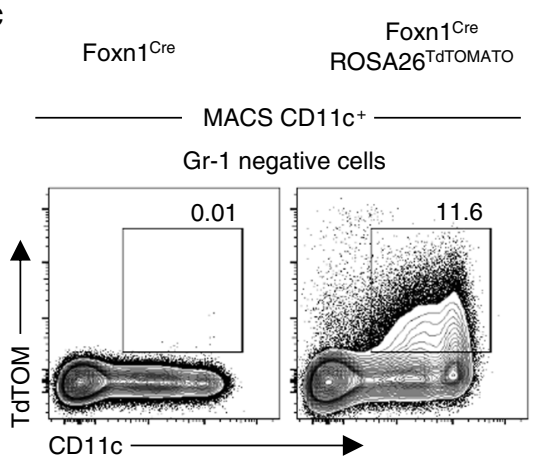

f

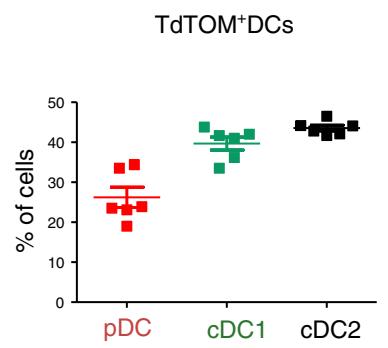

d

$\mathrm{TdTOM}^{+} \mathrm{CD} 11 \mathrm{c}^{+}$cells

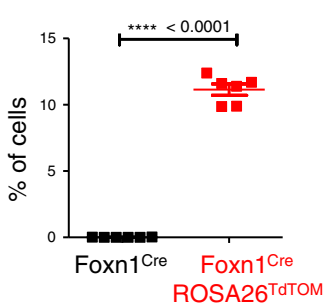

e

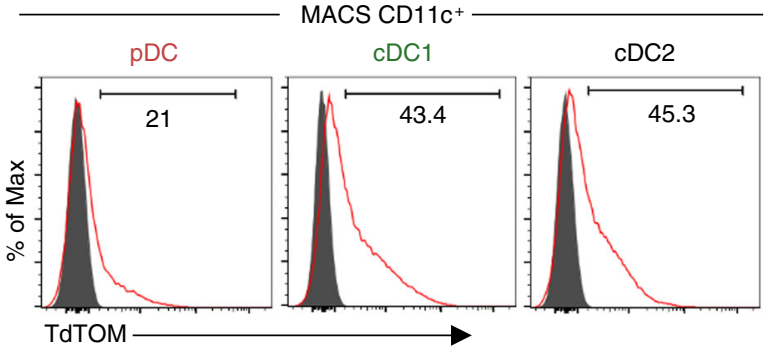

g

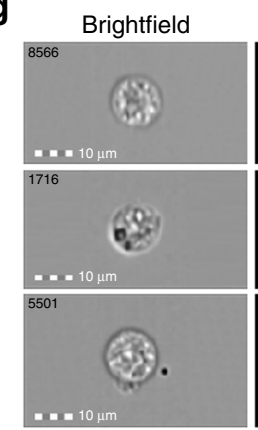

$\mathrm{MHCll}$

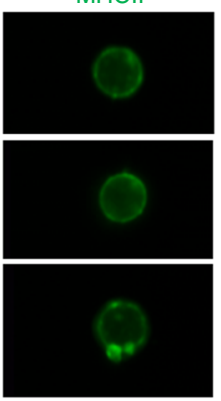

CD11C

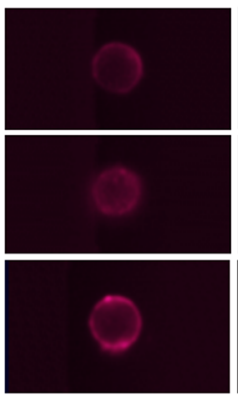

TdTOM

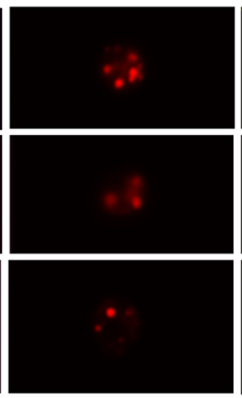

MHCII/TdTOM

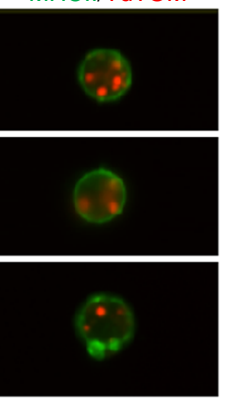

Fig. 4 Foxn1 ${ }^{\text {Cre ROSA26 }}{ }^{\text {TdTOMATO }}$ as a model of thymic cooperative antigen transfer. a Experimental design. b Flow cytometry heat-map analysis showing the intensity of TdTOM fluorescence among MACS TCR $\beta$-depleted cells from the thymus of the Foxn1CreROSA26 TdTOMATO mouse. $\mathbf{c}$ Representative flow cytometry plots comparing the frequency of $\mathrm{TdTOM}^{+} \mathrm{CD} 11 \mathrm{c}^{+}$cells in the thymic MACS-enriched CD11c ${ }^{+}$cells between the WT (Foxn1 ${ }^{\mathrm{Cre}}$ ) and Foxn1 ${ }^{\mathrm{Cre}}$ ROSA26 ${ }^{\mathrm{TdTOM}}$ mouse. Cells were pre-gated as live, singlets, and $\mathrm{Gr}-\mathrm{1}^{-}$. d Quantification of $\mathrm{TdTOM}^{+} \mathrm{CD} 11 \mathrm{c}^{+}$cells from $\mathrm{c}$ (mean \pm SEM, $n=6$ mice). Statistical analysis was performed by unpaired, two-tailed Student's $t$-test, $p<0.0001={ }^{\star \star \star \star}$. e Representative flow cytometry histograms showing the frequency of $\mathrm{TdTOM}^{+}$cells among pDC, cDC1, and cDC2 (gated as in Supplementary Fig. 4a). Gray histograms $=$Foxn1 Cre (control) mice, red histograms $=$ Foxn1 ${ }^{C r e}$ ROSA26 ${ }^{\text {TdTOM }}$ mice. $\mathbf{f}$ Quantification of frequencies of TdTOM ${ }^{+}$DCs among the indicated DC subsets (mean \pm $\mathrm{SEM}, n=6$ mice). $\mathbf{g}$ Representative images from the Imagestream analysis showing intracellular localization of transferred TdTOM in MHCII+CD11c ${ }^{+} \mathrm{DCs}$ from the thymus of Foxn1 ${ }^{\text {Cre ROSA26 }} 6^{\text {TdTOMATO }}(n=400$ measured cells).

analysis of the main DC subsets defined by markers revealed by ddSEQ analysis showed that the increase of TdTOM ${ }^{+}$DCs was mostly due to the specific enrichment of $\mathrm{CD} 14^{+}$moDCs (Figs. 5e, f), which also co-express chemokine receptors for ligands induced by TLR9/MyD88 signaling in mTECs (Figs. 2b, e and 5c). Concomitantly, we observed a decrease in $\mathrm{Mgl} 2{ }^{+} \mathrm{cDC} 2, \mathrm{Xcr}^{+}{ }_{\mathrm{cDC} 1 \mathrm{~b}}$, and $\mathrm{B}_{220^{+}} \mathrm{pDC}$ (Fig. 5e, f and Supplementary Fig. 6g). Importantly, and further confirming the need of MyD88 signaling for its recruitment, the decreased frequency of total Sirpa ${ }^{+}$DCs in the thymus of non-manipulated MyD88 ${ }^{\triangle \mathrm{TEC}}$ mice (Fig. $3 \mathrm{~b}$ ) was shown to be accounted specifically by the diminishment of the CD14 ${ }^{+}$moDC subset (Fig. 5g).

To find which of the chemokines described (in Fig. 2b, e) were responsible for $\mathrm{CD} 14^{+}$moDC migration to the thymus, we crossed $\mathrm{Cxcr} 2^{\mathrm{fl} / \mathrm{fl}}$ mice with the pan-hematopoietic driver Vav1 ${ }^{\mathrm{Cre}}$ to abrogate the signaling of its cognate ligands Cxcl1, 2, 3, and 5 that were among the most upregulated genes in mTECs after TLR9 stimulation. We observed no changes in the recruitment of $\mathrm{CD}_{14}{ }^{+}$moDC after TLR9 stimulation between $\mathrm{Cxcr} 2^{\mathrm{fl} / \mathrm{fl}}$ Vav1 ${ }^{\mathrm{Cre}}$ and WT mice (Supplementary Fig. 6h). This suggests, that together with ligands of Ccr2, (i.e. Ccl2, 7, 8, and 12) ${ }^{19}$, the ligands of $\mathrm{Ccr} 1, \mathrm{Ccr} 3$ or $\mathrm{Ccr} 5$, or their combinations ${ }^{36}$, regulate the entry of $\mathrm{CD} 14^{+}$moDC into the thymic medulla.

Together, TLR9/MyD88-dependent chemokine signaling in mTECs specifically targets the recruitment and subsequent CAT from the mTECs to Sirpa ${ }^{+} \mathrm{CD} 14^{+}$moDC subpopulation which exhibits a tangible capacity for antigen presentation.

TLR9/MyD88 signaling in mTECs affects Treg development. Previous studies have suggested that the development of thymic Tregs is dependent on antigen presentation by both mTECs and $\mathrm{DCs}^{6,17,47}$. Specifically, antigen presentation by $\operatorname{Sirpa}^{+} \mathrm{DCs}^{17}$ and/or alternatively by $\mathrm{CD} 8 \mathrm{a}^{+} \mathrm{CDC}^{6,10}$ was implied in the development of organ-specific Tregs. It has been also suggested that the increased ratio of Sirpa ${ }^{+}$DCs to $\mathrm{CD} 8 a^{+} \mathrm{cDC} 1$ leads to an enhanced production of thymic CD25 ${ }^{+}$Foxp3 $3^{+}$Tregs ${ }^{17,20}$. Since a decreased frequency of Sirpa ${ }^{+}$DCs (Fig. 3b), specifically CD $14^{+}$moDCs (Fig. 5g) was observed in the thymus of 
a
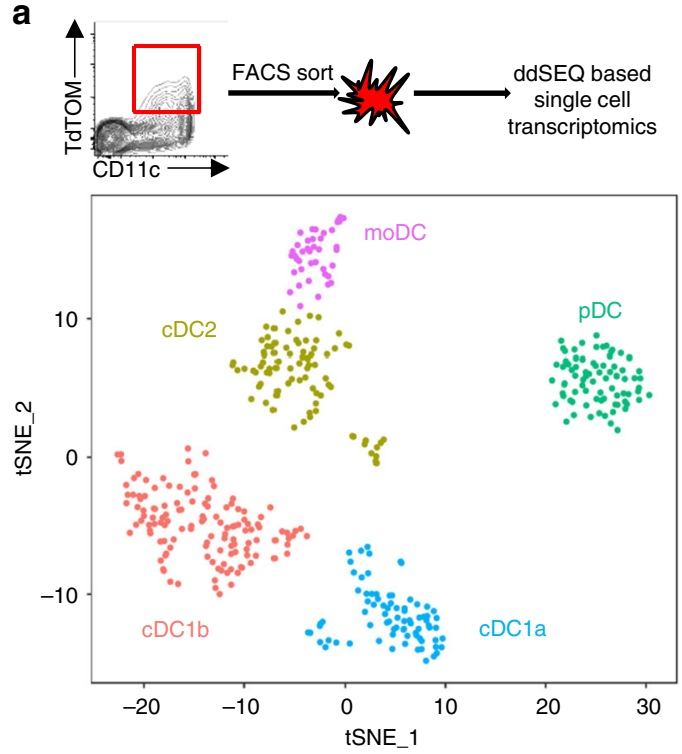

b
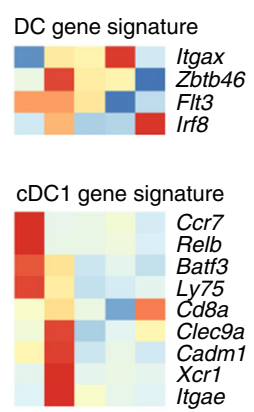

cDC2 gene signature

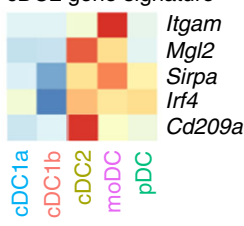

pDC gene signature

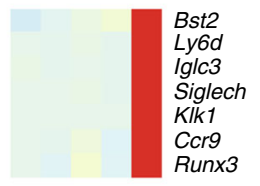

Monocyte/macrophage gene signature

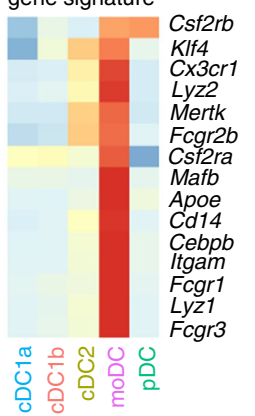

Monocyte gene signature

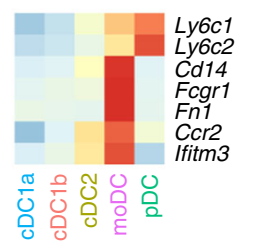

1.5
1
0.5

0

-0.5
-1
-1.5
C

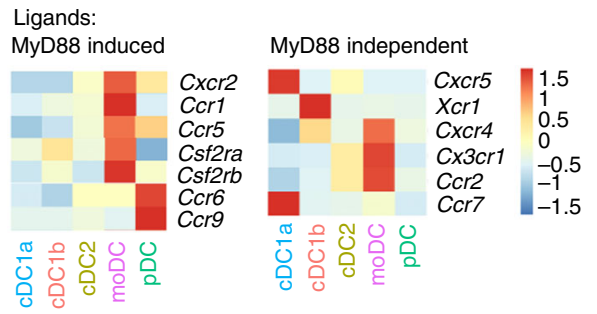

d

Foxn $1^{\text {Cre }}$ ROSA26 $6^{\text {TdTOMATO }}$

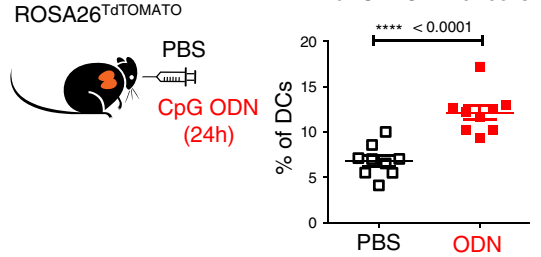

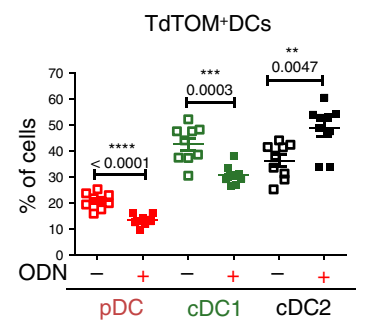

e
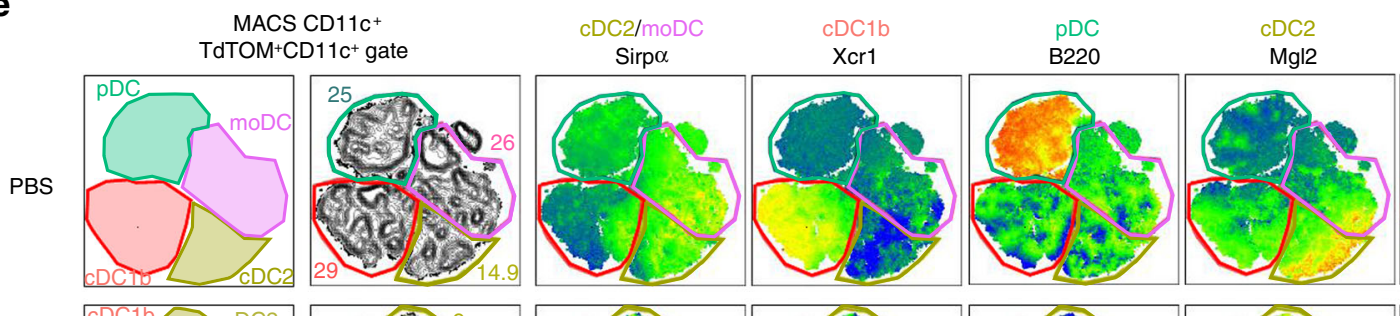

moDC
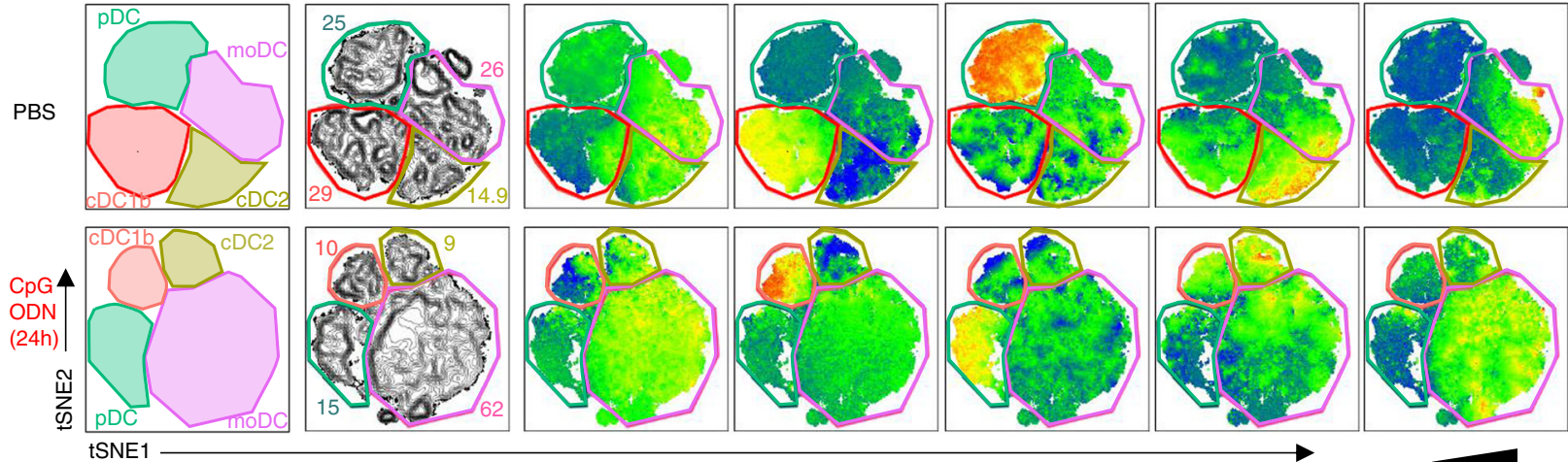

f Foxn $1^{\mathrm{Cre}}$

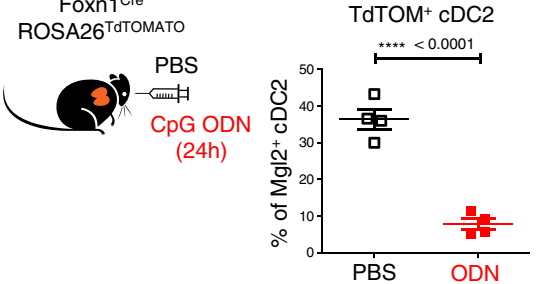

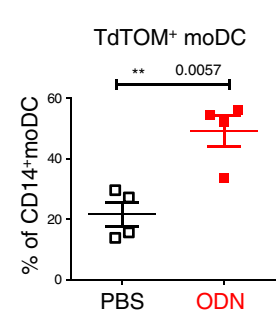

g

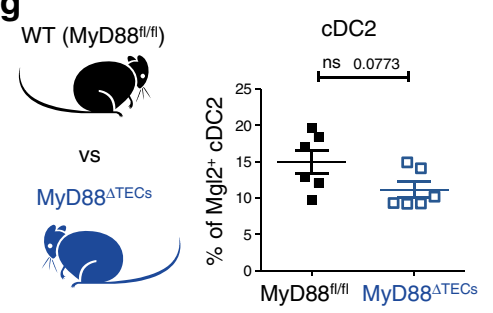

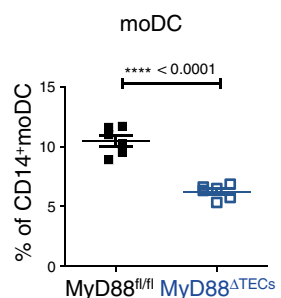

MyD88 ${ }^{\triangle T E C s}$ mice, we tested whether these effects would impact the development of the major thymocyte populations and Tregs. While the DN $\left(\mathrm{CD} 8^{-} \mathrm{CD} 4^{-}\right)$, DP $\left(\mathrm{CD} 8^{+} \mathrm{CD} 4^{+}\right)$, and $\mathrm{CD} 8^{+} \mathrm{T}$ cells frequencies were comparable between MyD $88^{\Delta \mathrm{TEC}}$ and WT mice, $\mathrm{CD} 4{ }^{+} \mathrm{T}$ cells, and more specifically $\mathrm{CD} 25^{+} \mathrm{Foxp} 3^{+}$Tregs were significantly reduced in 4-week-old MyD88 ${ }^{\triangle T E C s}$ mice (Fig. $6 \mathrm{a}-\mathrm{c}$ and Supplementary Fig. 7a). Since it has been reported that in 4 week-old-mice nearly one half of $\mathrm{CD} 25^{+}{ }^{F o x p} 3^{+}$thymic cells consist of mature recirculating Tregs ${ }^{48,49}$, we used $\mathrm{CD} 73$ protein staining to determine if Tregs reduced in MyD88 ${ }^{\Delta \mathrm{TECs}}$ mice were newly generated $\left(\mathrm{CD}^{-} 3^{-}\right)$or recirculating $\left(\mathrm{CD} 73^{+}\right)^{50}$. As shown in Fig. 6d, e, the abrogation of MyD88 signaling in mTECs affected mainly the generation of $\mathrm{CD} 25^{+} \mathrm{Foxp} 3^{+}$thymic Tregs and not their recirculation. On the other hand, the $\mathrm{CD} 25^{+} \mathrm{Foxp} 3^{+}$thymic Tregs 
Fig. 5 TLR/MyD88 signaling increases cooperative antigen transfer between TECs and the CD14 ${ }^{+}$moDC subpopulation. a Two-dimensional tSNE plot from ddSEQ single-cell RNA-sequencing from FACS sorted $\mathrm{Gr}_{-1} 1^{-} \mathrm{CD} 11 \mathrm{c}^{+} \mathrm{TdTOM}^{+}$DCs from the thymus of Foxn1 ${ }^{\mathrm{Cre}}$ ROSA26 $6^{\text {TdTOMATO }}$ mice. The color code represents different cell clusters based on the mRNA expression profile of each cell. $\mathbf{b}$ Heat-map analysis of the expression of signature genes determining each subset defined in a. c Heat-map analysis of the expression of chemokine receptors by DC subsets defined in a. $\mathbf{d}$ Quantification of $\mathrm{TdTOM}^{+} \mathrm{CD}_{11} \mathrm{C}^{+} \mathrm{DC}$ subsets (defined as in Supplementary Fig. 4a) in CpG ODN or PBS intrathymically stimulated Foxn1 ${ }^{\text {Cre ROSA26 }}{ }^{\text {TdTOMATO }}$ mice (representative flow cytometry plots are shown in Supplementary Fig. $6 \mathrm{~d}, \mathrm{f}$ ) (mean \pm SEM, $n=9$ mice). Statistical analysis was performed using unpaired, two-tailed Student's $t$-test, $p \leq 0.01={ }^{\star *}, p \leq 0.001^{\star \star \star}, p<0.0001^{\star \star \star \star}$. e Representative flow cytometry tSNE analysis of $\mathrm{TdTOM}^{+} \mathrm{CD} 11 \mathrm{c}^{+} \mathrm{cell}$ population in

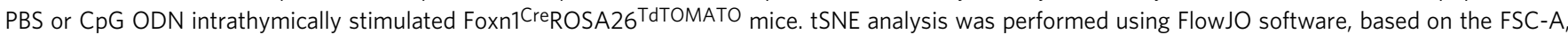
SSC-A, CD11c, MHCII, Sirp $\alpha$, Xcr1, B220, Mgl2 and CD14 markers ( $n=2$ independent experiments). $\mathbf{f}$ Quantification of frequencies of TdTOM + CD14+ moDC or $\mathrm{TdTOM}^{+} \mathrm{Mgl} 2^{+} \mathrm{CDC} 2$ from CpG ODN or PBS intrathymically stimulated Foxn1 Cre ROSA26 TdTOMATO mice (representative flow cytometry plots are shown in Supplementary Fig $6 \mathrm{~g}$ ) (mean $\pm \mathrm{SEM}, n=4$ mice). $\mathbf{g}$ Flow cytometry analysis comparing the frequency of $\mathrm{cDC2}\left(\mathrm{Sirp \alpha ^{+ }} M \mathrm{Mg} 2^{+}\right)$and $\mathrm{moDC}$ $\left(\mathrm{Sirp} \alpha^{+} \mathrm{CD} 14^{+}\right.$) between MyD88 ${ }^{\mathrm{fl} / \mathrm{fl}}$ and MyD88 $8^{\mathrm{TECs}}$ mice (mean $\pm \mathrm{SEM}, n=6$ mice). Total Sirp $\alpha^{+} \mathrm{DC}$ population was gated as shown in Supplementary Fig 4a. Statistical analysis in $\mathrm{f}$ and $\mathrm{g}$ was performed by unpaired, two-tailed Student's $t$-test, $p \leq 0.01={ }^{\star \star}, p<0.0001^{\star \star \star \star}$, ns not significant.

were not reduced in newborn MyD88 ${ }^{\Delta \mathrm{TECS}}$ (Supplementary Fig. 7b) or GF mice (Supplementary Fig. 7c) when compared to their WT SPF littermates. This, in association with unchanged chemokine expression in mTECs from GF mice, (Supplementary Fig. 2b) further strengthens the notion that the ligands that regulate the mTEC-mediated MyD88-dependent cellularity of Tregs is not likely of exogenous origin.

To further explore the MyD88-dependent regulation of Tregs generation, we tested our prediction that TLR9/MyD88 stimulation of mTECs would lead to the opposite effect, i.e. boosted number of Tregs. Indeed, seven days after intrathymic injection of CpG ODN, we observed a significant increase in the frequency and total number of $\mathrm{CD}_{25} 5^{+} \mathrm{Foxp}^{+}$thymic Tregs (Fig. $6 \mathrm{f}$ and Supplementary Fig. 7d-f). Importantly, this increase was completely dependent on TEC-intrinsic MyD88 signaling (Fig. 6f). Compared to the decreased numbers in $\mathrm{CD}^{-} 3^{-}$Tregs in MyD88 ${ }^{\Delta \mathrm{TEC}}$, intrathymic injection of CpG ODN led to increased numbers of not only CD73newly generated Tregs but also recirculating $\mathrm{CD} 3^{+}$Tregs (Fig. $6 \mathrm{~g}$ and Supplementary Fig. $7 \mathrm{~g}$ ). This suggests that there are other mTEC-dependent mechanisms which after $\mathrm{CpG}$ ODN stimulation can affect the recirculation of Tregs into the thymus. One outstanding question related to the results from the above experiments (Figs. $3 \mathrm{c}$ and $5 \mathrm{~d}-\mathrm{f}$ and Supplementary Fig. 6c) is whether the increased generation of thymic $\mathrm{CD} 25^{+} \mathrm{Foxp} 3^{+} \mathrm{CD} 73^{-}$ thymic Tregs is dependent on the antigen presenting capacity of DCs. To resolve this query, we intrathymically injected CpG ODN into $\mathrm{H} 2-\mathrm{Ab}^{\mathrm{Al} / \mathrm{fl}}$ Itgax $\mathrm{Cre}\left(\mathrm{H} 2-\mathrm{Ab}^{\mathrm{ADCs}}\right)$ mice, where antigen presentation by DCs has been abrogated. As demonstrated in Fig. $6 \mathrm{~h}$, $\mathrm{i}$ and Supplementary Fig. 7h, the presentation of antigen by DCs is essential for the increase in numbers of newly generated $\mathrm{CD}^{-}$ CD25 ${ }^{+} \mathrm{Foxp}^{+}$thymic Tregs after TLR9 stimulation.

Next, we tested the physiological consequences of the decrease in production of Tregs in MyD88 ${ }^{\Delta \mathrm{TECs}}$ mice. We took advantage of a $\mathrm{T}$ cell induced colitis model, where the adoptive transfer of naïve, Treg depleted $\mathrm{CD} 4^{+} \mathrm{T}$ cells into Rag1-deficient mice induces severe colitis ${ }^{51}$. In this experimental setup, and as illustrated in Fig. 7a, the i.p. injection of the $\mathrm{CD}^{+} \mathrm{T}$ cell population isolated from peripheral lymph nodes of either $\mathrm{MyD}^{\mathrm{ATEC}}$ or $\mathrm{MyD} 88^{\mathrm{f} / \mathrm{fl}}$ mice was compared to colitisinducing transfer of $\mathrm{CD} 4{ }^{+} \mathrm{CD} 45 \mathrm{RB}^{\text {high }} \mathrm{CD} 25^{-}$cells isolated from WT mice.

Strikingly, mice that received $\mathrm{CD} 4^{+} \mathrm{T}$ cells from MyD88 ${ }^{\Delta \mathrm{TEC}}$ began to lose weight $\sim 4$ weeks after adoptive transfer, behaving identically to the positive control. In contrast, mice that received $\mathrm{CD}^{+} \mathrm{T}$ cells from WT mice continuously gained weight over time (Fig. 7b). The clinical signs of colitis in mice receiving $\mathrm{CD} 4^{+} \mathrm{T}$ cells from $\mathrm{MyD} 88^{\triangle \mathrm{TEC}}$ and in the positive controls were manifested by the presence of inflammatory infiltrates in the colon lamina propria, increased bowel wall thickness, presence of abscesses in colon tissue (Fig. 7c), increased spleen weight (Supplementary
Fig. 8a, b), and a higher colon weight/length ratio (Fig. $7 \mathrm{~d}$ and Supplementary Fig. 8a). To confirm the persistence of the transferred $\mathrm{T}$ cell population, we also analyzed Tregs frequencies in all conditions. We found that both positive controls and mice that received $\mathrm{CD}^{+} \mathrm{T}$ cells from MyD88${ }^{\triangle \mathrm{TECs}}$ had severely diminished Tregs compared to WT controls (Fig. 7e). The very similar phenotype of mice that received $\mathrm{CD}^{+} \mathrm{T}$ cells from MyD88 ${ }^{\triangle \mathrm{TECs}}$ and those which received $\mathrm{CD} 4{ }^{+} \mathrm{CD} 45 \mathrm{RB}^{\text {high }} \mathrm{CD} 25^{-}$ suggested, that Tregs in MyD88 ${ }^{\triangle T E C s}$ were not only reduced in numbers but also functionally altered. Along with the decreased expression of CD25 (Fig. 7f), Tregs from MyD88 ${ }^{\Delta T E C s}$ mice showed a significantly reduced capacity to suppress the proliferation of OVA-specific OT-II T cells in vitro (Fig. 7g, h) and prevent the early onset of diabetes caused by activated KLGR1 ${ }^{+}$OT-I $\mathrm{T}$ cells in a RIP-OVA dependent autoimmune mouse model ${ }^{52}$ (Supplementary Fig. 8c-e).

Taken together, these results demonstrate that TLR/ MyD88 signaling in TECs affects the development of thymic $\mathrm{CD} 25^{+}$Foxp $3^{+}$Tregs. Specifically, in mice with MyD88-deficient TECs, the frequency and functionality of thymic $\mathrm{CD} 25^{+} \mathrm{Foxp} 3^{+}$ Tregs was decreased and unable to prevent $\mathrm{T}$ cell induced colitis.

\section{Discussion}

Present study lends a support for the role of TLR signaling in the mechanism of central tolerance. First, we found that mTECshigh express TLRs, including TLR9, whose signaling is functionally wired to the expression of chemokines and genes associated with their post-Aire development. Second, the receptors for these chemokines are predominantly expressed by the Sirpa ${ }^{+}$thymic population of $\mathrm{CD}_{1} 4^{+}$moDCs whose enrichment in the thymus and subsequent CAT is positively regulated by mTEC-intrinsic TLR/MyD88 signaling. Third, TLR/MyD88 signaling in mTECs is important for the proper development of thymic $\mathrm{CD} 73^{-} \mathrm{CD} 25^{+} \mathrm{Foxp} 3^{+}$Tregs since its abrogation resulted in a decreased number and the functionality of Tregs, associated with pathological effects in the mouse model of colitis.

The importance of TLR/MyD88 signaling in Aire-dependent autoimmunity was suggested in experiments conducted with MyD88 $^{-/-}$Aire $^{-/}$double-knockout mice. These mice develop more severe symptoms of autoimmunity than $\mathrm{Aire}^{-/-}$single KO animals indicating the positive regulatory role of MyD88 signals in tolerance induction. Strikingly, neither the enhancement of MyD88 signals by an i.p. injection of TLR ligands, nor their diminishment in mice from GF conditions altered the severity of Aire-dependent autoimmunity ${ }^{53}$. Our data advocates for a scenario in which the worsening of autoimmunity in MyD88 ${ }^{-/-}$ Aire $^{-/-}$mice could be caused by the lack of MyD88 signaling in mTECshigh, downregulation of their chemokines needed to 
a

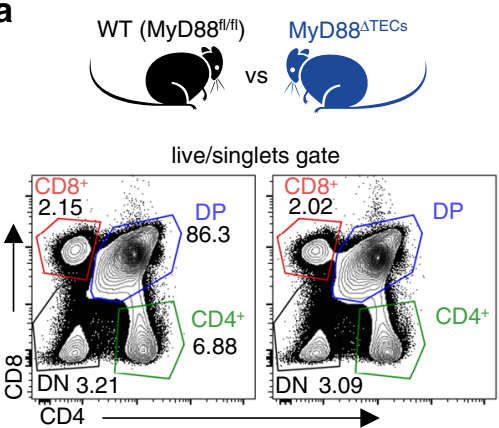

b

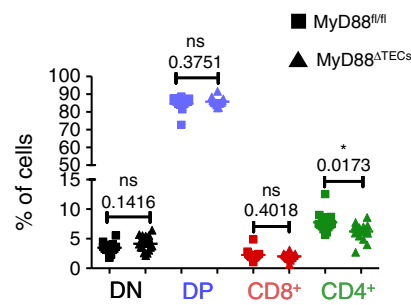

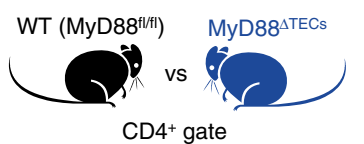

C

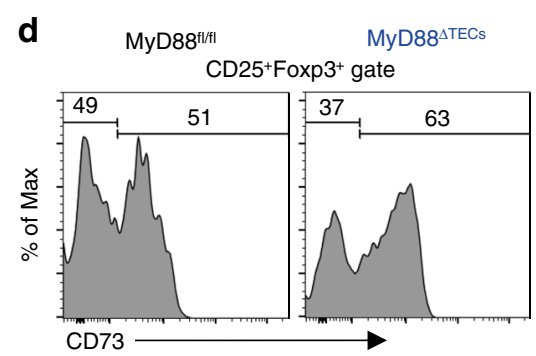

e
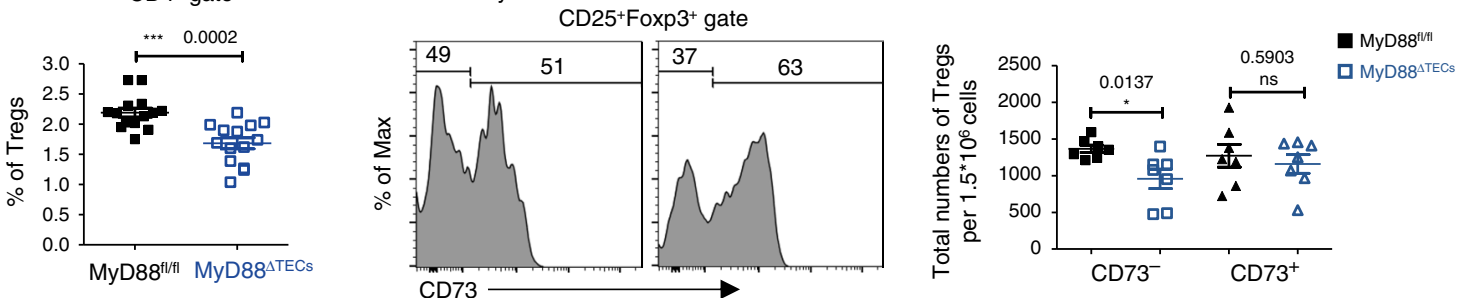

f
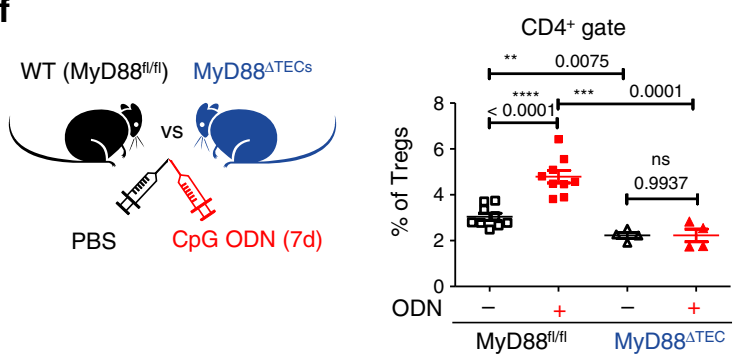

g

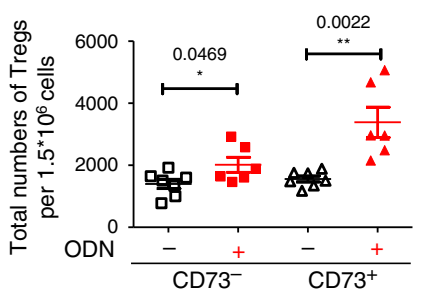

h
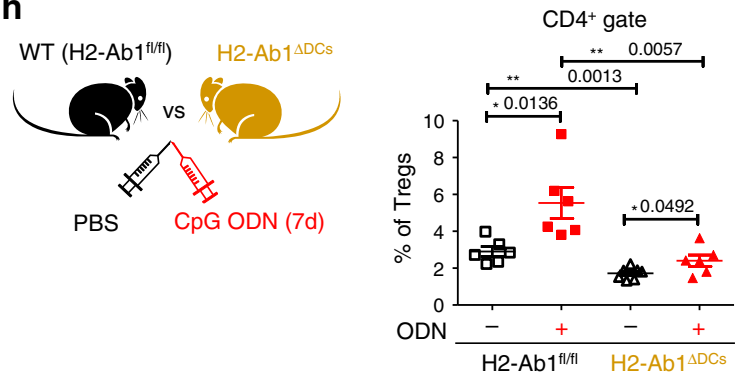

i

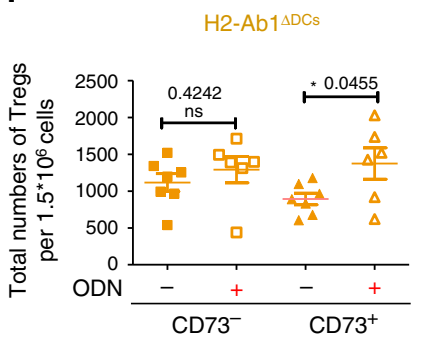

Fig. 6 Development of thymic Tregs is impaired in MyD88 ${ }^{\Delta T E C s}$ mice. a Representative flow cytometry plots (left plot) and their quantification (right plot) comparing the frequencies of main thymic T cell populations between MyD $88^{\mathrm{fl} / \mathrm{fl}}$ and MyD8 $88^{\Delta \mathrm{TECs}}$ mice (mean $\pm \mathrm{SEM}, n=14$ mice). b Representative flow cytometry plots comparing the frequencies of CD4+CD25+Foxp3+ thymic Tregs between MyD88 ${ }^{f / / f l}$ and MyD88 ${ }^{\Delta T E C s}$ mice. c Quantification of frequencies from b (mean $\pm \mathrm{SEM}, n=14$ mice). d Representative flow cytometry histograms showing the expression of CD73 by CD4 ${ }^{+}$ $\mathrm{CD}_{2} 5^{+}$Foxp3 $3^{+}$thymic Tregs (gated as in b). e Quantification of the total numbers of CD73- and CD73+ thymic Tregs from d (mean \pm SEM, $n=7$ mice). f Quantification of the frequencies of thymic Tregs from CpG ODN or PBS intrathymically stimulated (7 days) MyD88 $8^{\mathrm{fl} / \mathrm{fl}}$ or MyD88 $8^{\Delta \mathrm{TECs}}$ mice (mean \pm SEM, $n=4$ for MyD88 ${ }^{\Delta T E C s}$ and $n=9$ for MyD88 $8^{\mathrm{fl} / \mathrm{fl}}$ mice). $\mathbf{g}$ Quantification of the total numbers of CD73- and CD73 ${ }^{+}$thymic Tregs from CpG ODN or PBS intrathymically stimulated (7 days) WT (C57BI/6J) mice (mean \pm SEM, $n=6$ for ODN ${ }^{+}$and $n=7$ for ODN ${ }^{-}$mice). $\mathbf{h}$ Quantification of frequencies of thymic Tregs from CpG ODN or PBS intrathymically stimulated (7 days) $\mathrm{H} 2-\mathrm{Ab} 1^{\mathrm{fl} / \mathrm{fl}}$ or $\mathrm{H} 2-\mathrm{Ab} 1^{\mathrm{fl} / \mathrm{fl} \mid \operatorname{tgax} \mathrm{Cre}}\left(\mathrm{H} 2-\mathrm{Ab} 1^{\Delta \mathrm{DCs}}\right)$ mice $(\mathrm{mean} \pm \mathrm{SEM}, n=6 \mathrm{for}$ $\mathrm{H} 2-\mathrm{Ab}^{\mathrm{fl} / \mathrm{fl}}$ and $\mathrm{ODN}{ }^{+} \mathrm{H} 2-\mathrm{Ab} 1^{\triangle \mathrm{DCs}}$ and $n=7$ for ODN ${ }^{-} \mathrm{H} 2-\mathrm{Ab} 1^{\Delta \mathrm{DCs}}$ mice). i Quantification of the total numbers of $\mathrm{CD}^{-} 3^{-}$and $\mathrm{CD}^{-} 3^{+}$thymic Tregs from CpG ODN or PBS intrathymically stimulated (7 days) H2-Ab1 $\triangle \mathrm{DCs}$ mice (mean $\pm \mathrm{SEM}, n=6$ for $\mathrm{ODN}^{+}$and $n=7$ for ODN $\mathrm{ON}^{-}$mice). Statistical analysis in $\mathbf{a}, c$, e-i was performed by unpaired, two-tailed Student's $t$-test, $p \leq 0.05={ }^{\star}, p \leq 0.01={ }^{\star \star}, p \leq 0.001^{\star \star \star} p<0.0001^{\star \star \star \star}$, ns not significant.

recruit $\mathrm{CD} 14^{+}$moDCs and, consequently, suboptimal production of thymic Tregs. Consistent with the previous report ${ }^{53}$, we confirmed that the extrathymically enhanced (i.p. CpG ODN) or the lack of bacterially-derived MyD88 signals (GF mice) had no effect on the expression level of these chemokines and cytokines in WT mice. This was further corroborated by the fact that GF mice displayed normal numbers of Tregs ${ }^{50}$ (Supplementary Fig. 7c).
This data demonstrates that the ligand triggering TLR9/ MyD88 signaling in mTECs ${ }^{\text {high }}$ is likely of endogenous thymicderived origin.

Since MyD88 also conveys signals from the receptors of IL-1 family cytokines (IL-1 $\beta$, IL-18, IL-33) $)^{38}$, we tested in vitro whether their signaling in mTECshigh could trigger chemokine responses similar to those observed upon TLR9 stimulation. Of 

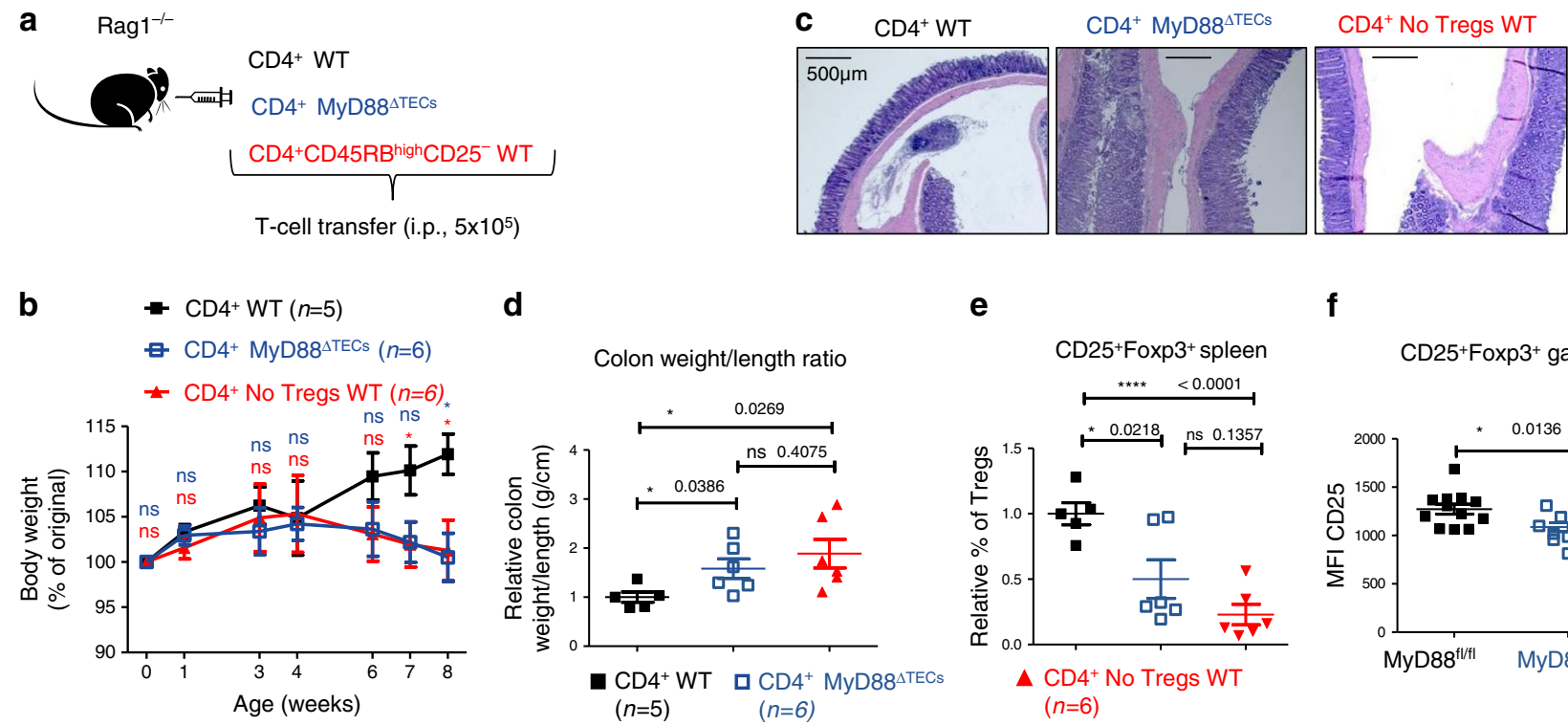

f
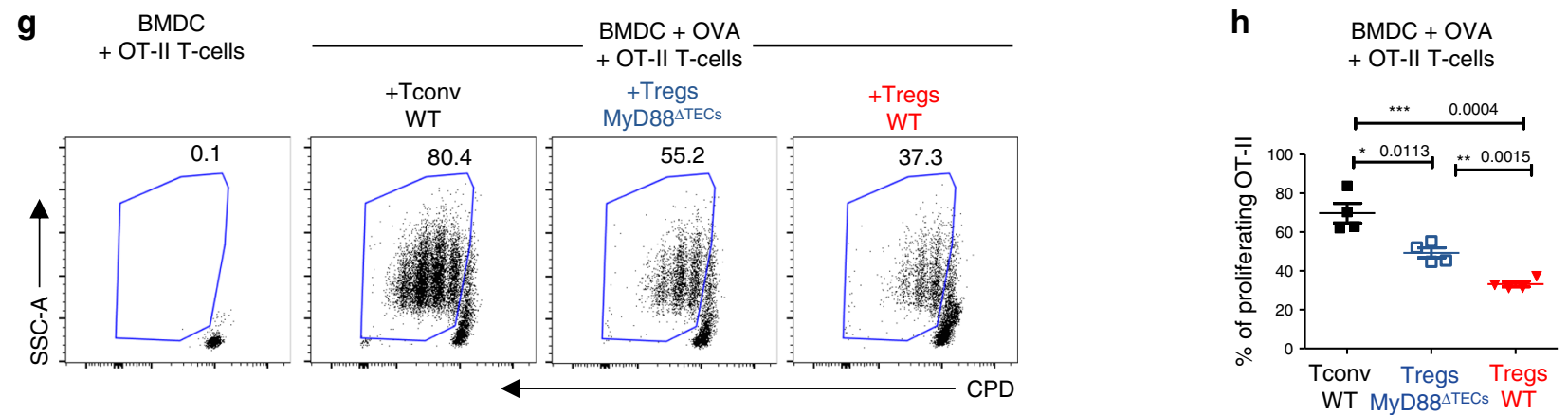

Fig. 7 Tregs from MyD88 ${ }^{\Delta T E C s}$ mice have reduced suppressive capacity and failed to prevent the $\mathbf{T}$ cell induced colitis. a Experimental design of induced colitis. b Relative quantification of mice weight normalized to its value on day 0 (100\% of original weight) after T cell transfer over the time-course of the colitis experiment (mean \pm SEM,$n=5-6$ mice) Statistical analysis was performed by unpaired, two-tailed Student's $t$-test comparing the relative weight of WT CD4 ${ }^{+}$with MyD88 ${ }^{\Delta \mathrm{TECs}} \mathrm{CD} 4^{+}$transferred mice (blue) or with WT $\mathrm{CD}^{+}{ }^{+} \mathrm{CD} 45 \mathrm{RB}^{\text {high }} \mathrm{CD}^{2} 5^{-}$transferred mice (red), $p \leq 0.05={ }^{\star}$, ns not significant. c Representative H\&E-stained slides of colon sections performed 8 weeks after T cell transfer. Scale bar represents $500 \mu \mathrm{m}(n=5$ for $\mathrm{CD} 4+\mathrm{WT}$ and $n=6$ for CD4 ${ }^{+}$MyD88 $\Delta \mathrm{TECs}$ and CD4 ${ }^{+}$No Tregs WT mice). d Relative quantification (normalized to average of control mice from each experiment) of colon weight/length ratio of T cell induced colitis experimental mice (mean \pm SEM, $n=5-6$ mice). e Relative quantification of the frequencies (normalized to average of control mice from each experiment) of $\mathrm{CD} 4{ }^{+} \mathrm{CD} 25^{+}$Foxp3 ${ }^{+}$Tregs isolated from the spleens of experimental mice 8 weeks after $T$ cell transfer (mean \pm SEM, $n=5-6$ mice). $\mathbf{f}$ Quantification of the Means fluorescent intensity (MFI) of CD25 protein expression in CD25 ${ }^{+}$Foxp3 ${ }^{+}$Tregs (gated as in Fig. $6 \mathrm{~b}$ ) in MyD88 ${ }^{\mathrm{fl} / \mathrm{fl}}$ and MyD88 ${ }^{\Delta \mathrm{TECs}}$ mice (mean $\pm \mathrm{SEM}, n=12$ mice) Statistical analysis in $\mathbf{b}$, $\mathbf{d}-\mathbf{f}$ was performed by unpaired, two-tailed Student's $t$-test, $p \leq 0.05={ }^{\star}, p<0.0001^{\star \star \star \star}$, ns not significant. $\mathbf{g}$ Representative flow cytometry plots showing the frequency of proliferating OT-II T cells, co-cultivated with OVA pulsed BMDC and CD4+CD25+ Tregs cells (alternatively with CD4 ${ }^{+}$CD25- Tconv cells, black) isolated from LNs of MyD88 $8^{\mathrm{fl} / \mathrm{fl}}$ (WT control, red) or MyD88 ${ }^{\Delta T E C s}$ (blue) for $72 \mathrm{~h}$. h Quantification of frequencies of proliferating OT-II Tcells form $\mathrm{h}$ (mean \pm SEM, $n=4$ wells from two independent experiments).

this trio of cytokines, only IL- $1 \beta$ exhibited this capacity. This indicates that IL- $1 \beta$ could act as a co-regulator of chemokines and cytokine expression in mTECs ${ }^{\text {high }}$. However, two observations suggest that TLR9/MyD88 signaling axis can act independently of IL-1 $\beta$ : (i) a direct, in vitro, stimulatory capacity of CpG ODN induces chemokine expression in sorted mTECshigh; and (ii) both in vivo intrathymic stimulation of TLR9/MyD88 signaling axis as well as its downregulation in MyD88 ${ }^{\triangle T E C s}$ cells impacts the recruitment of the very same subsets of $\mathrm{CD} 14^{+}$moDCs.

It has been postulated that Aire ${ }^{+}$mTECs further differentiate into post-Aire cells, which downregulate the expression of MHCII and Aire, upregulate a set of genes, such as keratins (Krt1, 10,77) or involucrin and form Hassall's corpuscules ${ }^{40,41,54}$. However, the regulatory mechanism(s) guiding this differentiation process remains poorly understood ${ }^{55}$. Our transcriptomic results are consistent with the idea that TLR/MyD88 signaling establishes an expression profile that is associated with the differentiation of mTECs ${ }^{\text {high }}$ into post-Aire mTECs. Notably, TLR9 stimulation not only increased the number of Involucrin ${ }^{+}$post-Aire mTECs (Supplementary Fig. 3e, f), but also lead to the upregulation of cytokines and chemokines (Illf6, Lcn2, Cxcl3, and Cxcl5) associated with Hassall's corpuscles ${ }^{42}$ which attract $\mathrm{CD} 14^{+}$moDCs. Together with the fact that they serve as a reservoir of a large amount of Aire-dependent TRAs, post-Aire mTECs could hold central position in the mechanism of transfer of mTEC-derived antigens to thymic DCs.

As described above, TLR/MyD88 signaling in mTECshigh drive the expression of chemokines which act on an overlapping set of receptors ${ }^{32}$ predominantly expressed by $\mathrm{CD} 14^{+}$moDCs (Cxcr2, Ccr1, Ccr3, Ccr5) and pDCs (Ccr5, Ccr6, and Ccr9). A correlative nature between the frequency of $\mathrm{CD} 14^{+} \mathrm{moDC}$ in the thymus of MyD $88^{\triangle T E C s}$ and of WT stimulated with CpG, underpins the 
importance of these chemokines in controlling the migration of these cells into the thymic medulla. However, the deletion of Cxcr2 on hematopoietic cells, the common receptor for Cxcl1, $\mathrm{Cxcl} 2, \mathrm{Cxcl} 3$ and $\mathrm{Cxcl} 5$, did not yield any changes in the enrichment of $\mathrm{CD} 14^{+} \mathrm{moDC}$ in the thymus (Supplementary Fig. 6h). This observation, in conjunction with previous reports ${ }^{18,56}$, allows one to predict that while the ligands of Ccr3 and/or $\mathrm{Ccr} 5(\mathrm{Ccl} 3, \mathrm{Ccl} 4, \mathrm{Ccl} 5$ or $\mathrm{Ccl} 24)$ likely regulate the entry of $\mathrm{CD}_{14}{ }^{+}$moDC into the thymus ${ }^{19}$, Cxcl-chemokines may regulate the positioning of these cells in close proximity of post-Aire mTECs. Interestingly, with the decreased frequency of CD14 ${ }^{+}$ moDCs in the thymus of $\mathrm{MyD} 88^{\triangle \mathrm{TEC}}$, pDCs were similarly diminished. However, in contrast to $\mathrm{CD} 14^{+}$moDCs, the number of pDCs did not increase after TLR9 intrathymic stimulation. This is consistent with the fact that the migration of $\mathrm{pDCs}$ to the thymus is driven by $\mathrm{Ccl} 25$ (ligand of $\mathrm{Ccr} 9$ receptor) ${ }^{14}$, the expression of which was diminished in MyD88 ${ }^{\triangle T E C}$ but was not upregulated in WT mTECs after TLR9 stimulation.

It has been previously documented that specific subtypes of thymic DCs vary in their capacity to acquire antigens from TECs. Notably, while the transfer of MHC molecules from TECs to CD8 $\alpha^{+}$ CDC1 and Sirpa ${ }^{+}$DCs occurred at the same efficiency ${ }^{16}$, the transfer of intracellular GFP was restricted mainly to $\mathrm{CD} 8 \mathrm{a}^{+} \mathrm{CDC1} 1^{10}$. In comparison, our data shows that cytoplasmic TdTOM from Foxn1 ${ }^{\text {Cre }}$ ROSA26 ${ }^{\text {TdTOMATO }}$ could to certain extent, be transferred to all major subtypes of thymic DCs. This may be explained by the robustness of the Foxn $1^{\mathrm{Cre}}$-dependent system where, compared to Aire-GFP model, the production of TdTOM is not restricted only to Aire-expressing mTECs but to the entire thymic TEC population. Importantly, since the CAT of TdTOM after CpG ODN intrathymic injection is increasingly targeted to $\mathrm{CD} 14^{+}$moDC subpopulation, the efficiency of CAT correlates not only with the broadness of antigen expression but also with the frequency of a given DC subtype in the medulla. On the other hand, since TECs constitute a relatively rare cell population of thymic cells ${ }^{57}$, the amount of antigen, which can be potentially transferred to DCs, is fairly limited. This could explain the fact that even when the entire population of thymic pDCs is not affected by intrathymic TLR9 stimulation, the frequency of $\mathrm{TdTOM}^{+}$pDCs is significantly decreased, due to the increased competition for TdTOM uptake by $\mathrm{CD} 14^{+}$moDCs.

It has become clear that developing thymocytes encounter selfantigens presented by various types of thymic APC, including mTECs $^{47}, \mathrm{~B}-$ cells $^{58}, \mathrm{pDCs}^{14}$, and $\mathrm{cDCs}^{11,59}$. Although the generation of thymic Tregs was shown to be dependent on antigen presentation by both mTECs and DCs ${ }^{4,47}$, thymic CDCs seem to be particularly important for this process ${ }^{6,17,60}$. Along with selfantigen presentation, thymic cDCs express high levels of costimulatory molecules CD80/86 as well as CD70 which play a crucial role in promoting thymic Treg development ${ }^{61,62}$. Among cDCs, Sirpa ${ }^{+}$DCs are the most efficient in supporting Treg generation $17,20,63$. In this context, our data demonstrates that the development of thymic CD25 ${ }^{+}$Foxp3 ${ }^{+}$Tregs is boosted by TLR/ MyD88 signaling in TECs, which produce a chemokine gradient driving the migration of $\mathrm{CD} 14^{+}$moDCs into the thymus. We also found that mTEC-intrinsic TLR9/MyD88 signaling increased the cell ratio of Sirpa ${ }^{+} \mathrm{DCs}$ to $\mathrm{Xcr} 1^{+} \mathrm{CDC} 1$, which correlated with an increased production of thymic Tregs. These findings accurately recapitulate the thymic phenotype of $\mathrm{Ccr}^{-1-}$ mice where the increased ratio of Sirpa ${ }^{+}$DCs to $\mathrm{CDC} 1$ correlated with the increased generation of thymic Tregs ${ }^{20}$. This data, together with the fact that abrogation of MHCII-antigen presentation specifically in DCs, resulted in a reduced number of thymic Tregs in unstimulated ${ }^{17}$ as well as in CpG stimulated thymus (Fig. 6h), suggest that TLR/MyD88-dependent generation of thymic Tregs is mediated by antigen-presentation by DCs.
Our results also show that TLR/MyD88 signalling in mTECs drives the recirculation of mature $\mathrm{CD} 73^{+} \mathrm{CD} 25^{+}$Foxp $3^{+}$Tregs into the thymus. Compared to newly generated $\mathrm{CD}^{-} 3^{-}$Tregs, their increased number in the TLR9 stimulated thymus was not dependent on MHCII presentation by DCs. Together, with the fact that recirculation of $\mathrm{CD}^{+} 3^{+}$Tregs was not abrogated in MyD88 $\triangle$ TECs mice, suggests that Ccl20, the ligand for Ccr6, which is highly expressed by recirculating Tregs ${ }^{64}$ regulates the increased recirculation of $\mathrm{CD} 73^{+} \mathrm{CD} 25^{+}$Foxp $3^{+}$Tregs into the thymus after TLR9 intrathymic stimulation (Figs. $2 \mathrm{~d}$ and e).

Altogether, our model proposes that TLR/MyD88 signaling in mTECs regulates the generation of Tregs. The mechanism involves TLR-induced chemokine production and subsequent chemotactic recruitment of $\mathrm{CD} 14^{+}$moDC to the thymic medulla, which predicates the developmental output of Tregs. Although this study explores only TLR9 signaling in mTECs, questions surrounding the nature of potential thymic-derived endogenous ligands for TLR/MyD88 signals in mTECs remains enigmatic and warrant further study.

\section{Methods}

Mice. A majority of the mice used in this study were of C57BL/6J genetic background and housed in the animal facility at the Institute of Molecular Genetics of the ASCR v.v.i. under SPF conditions. Mice were fed with irradiated standard rodent high energy breeding diet (Altromin 1314 IRR) and given reverse osmosis filtered and chlorinated water ad libitum. Light were adjusted to a $12 \mathrm{~h} / 12 \mathrm{~h}$ light/ dark cycle; temperature and relative humidity were maintained at $22 \pm 1^{\circ} \mathrm{C}$ and $55 \pm$ $5 \%$, respectively. Experimental protocols were approved by the ethical committee of the Institute of Molecular Genetics and by the ethical committee of the Czech Academy of Science. Aire ${ }^{-/-}$(B6.129S2-Aire ${ }^{\text {tm1.1Doi } / J, ~ s t o c k \# ~ 004743) ~}{ }^{2}$, Foxn1 ${ }^{\text {Cre }}$

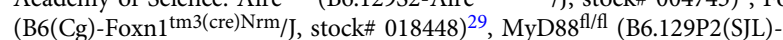

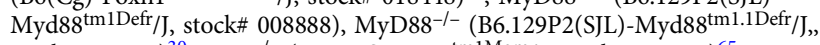
stock\# 009088) ${ }^{30}, \mathrm{Rag}^{-1-}\left(\mathrm{B} 6.129 \mathrm{~S} 7-\mathrm{Rag} 1^{\mathrm{tm} 1 \mathrm{Mom} / \mathrm{J}}\right.$, stock\# 002216) ${ }^{65}$, Ly5.1 (B6. SJL-Ptprc ${ }^{\mathrm{a} P e p c}$ b/BoyJ, stock\# 002014) ${ }^{66}, \mathrm{Cxcr}^{\mathrm{fl} / \mathrm{fl}}\left(\mathrm{C} 57 \mathrm{BL} / 6-\mathrm{Cxcr} 2^{\text {tm1Rmra/J, stock\# }}\right.$ $024638)^{67}, \mathrm{H} 2-\mathrm{Abl}^{\mathrm{f} / \mathrm{fl}}\left(\mathrm{B} 6.129 \times 1-\mathrm{H} 2-\mathrm{Ab}^{\mathrm{tm} 1 \mathrm{Koni}} / \mathrm{J} \text {, stock\# } 013181\right)^{68}$, and Itgax Cre (B6.Cg-Tg(Itgax-cre)1-1Reiz/J, stock\# 008068 ${ }^{69}$ mice were purchased from Jackson Laboratories. Rosa26 TdTOMATO (B6;129S6-Gt(ROSA)26 Sortm14(CAG-tdTomato)Hze/J, stock\# 007908) ${ }^{70}$ and Vavl ${ }^{\text {Cre }}$ (B6.Cg-Commd10 Tg(Vavl-icre)A2Kio/J, stock\# 008610) ${ }^{71}$ were kindly provided by V. Kořínek (Institute of Molecular Genetics of the ASCR, Prague, Czech Republic). Aire-HCO (Balb/c) ${ }^{4}$ were provided by L. Klein. Cd3 $3 \varepsilon^{-1-72}$, RIP-OVA $^{73}$, OT-I ${ }^{+} \mathrm{Rag}_{2}{ }^{-/-74}$ (all C57BL/6J) were provided by O. Štěpánek. OT-II (B6.Cg-Tg(TcraTcrb)425Cbn/J, stock\# 004194 $)^{75}$ mice were kindly provided by $\mathrm{T}$. Brdička (Institute of Molecular Genetics of the ASCR, Prague, Czech Republic). C57BL/6J GF and control C57BL/6J SPF mice were kindly provided by $\mathrm{M}$. Schwarzer (Institute of Microbiology of the ASCR, Nový Hrádek, Czech Republic. Both GF and control SPF mice were subject to the SSNIFF V1124-300 diet. Thymic cell populations were isolated from 3-6-week-old mice with the exception of newborn mice (4 days old) used in Supplementary Fig. 7b. For the purpose of BM chimera experiments, 5-6-week-old mice were irradiated and analysed between 11 and 13 weeks of age. Comparative analysis used age-matched cohorts regardless of sex and caging. Where possible, littermates were used as the controls. For the purpose of tissue isolation, mice were euthanized by cervical dislocation.

Tissue preparation and cell isolation. Thymic antigen presenting cells, TECs and DCs, were isolated as follows. Thymus was minced into small pieces and treated with Dispase II (Gibco), dissolved in RPMI at concentration $0.1 \mathrm{mg} \mathrm{ml}^{-1}$. Tissue was homogenized by pipetting and after $10 \mathrm{~min}$ of incubation $\left(37^{\circ} \mathrm{C}\right)$, the supernatant was collected and the reaction was stopped by adding 3\% FSC and $2 \mathrm{nM}$ EDTA. The process was repeated until all thymic fragments were digested. For detail description see ${ }^{76}$. For thymic epithelial cells isolation, the whole thymic cell suspension was depleted of $\mathrm{CD} 45^{+}$cells by CD45 microbeads staining (Miltenyi biotec). Thymic dendritic cells were isolated using MACS enrichment for CD11c ${ }^{+}$ cells through staining with biotinylated CD11c antibody, followed by Ultrapure Anti-Biotin microbeads staining (Miltenyi biotec). For isolation of T cell, thymus, peripheral lymph nodes ( $\mathrm{pLN})$, mesenteric lymph nodes $(\mathrm{mLN})$ or spleen were mechanically mashed through $40 \mu \mathrm{m}$ Cell strainer (Biologix) and cell suspensions were passed through $50 \mu \mathrm{m}$ filters (Sysmex). The resulting cell suspension was spun down $\left(4^{\circ} \mathrm{C}, 400 \mathrm{~g}, 10 \mathrm{~min}\right)$ and erythrocytes were removed using ACK lysis buffer.

Flow cytometry analysis and cell sorting. Flow cytometry (FACS) analysis and cell sorting were performed using BD LSR II and BD Influx (BD Bioscience) cytometers, respectively. For surface staining, cells were incubated for 20-30 min at $4{ }^{\circ} \mathrm{C}$ with the indicated fluorochrome- or biotin-conjugated antibodies. Where necessary, cells were further incubated with streptavidin conjugates for $15 \mathrm{~min}$. 
Dead cells were excluded using Hoechst 33258 (Sigma) or viability dye eFlour 450 or 506 (eBioscience). For the intracellular staining of Aire and Foxp3, the cells were first stained for the targeted surface molecules, fixed, and permeabilized for $30 \mathrm{~min}$ at room temperature (RT) using the Foxp3/Transcription Factor Staining Buffer Set (eBioscience), then stained for $30 \mathrm{~min}$ at RT with fluorochrome-conjugated antibodies. FlowJO V10 software (Treestar) and BD FACSDiva ${ }^{\text {tw }}$ Software v6.0 for $\mathrm{BD}^{\mathrm{m}}$ LSR II (with HTS Option) was used for FACS data analysis including tSNE analysis shown in Fig. 5e. A complete inventory of staining reagents is listed in Supplementary Data 6.

Imaging flow cytometry. Imaging flow cytometry was performed at the Center for Advanced Preclinical Imaging (CAPI) with the use of AMNIS ImageStream X MkII (AMNIS). DCs isolated from Foxn1 CreROSA26 ${ }^{\mathrm{TdTOMATO}}$ mice were stained for the surface markers MHCII and CD11c. Dead cells were excluded by Hoechst 33258 staining and bright field analysis. Cells were recorded using 40x magnification. Data was analyzed with Ideas 6.1 software (AMNIS). A complete list of staining reagents can be found in Supplementary Data 6.

\section{In vitro TLRs and cytokines stimulation assays. TTECs $^{\text {high }}$ were gated as} $\mathrm{EpCAM}^{+} \mathrm{CD} 11 \mathrm{c}^{-} \mathrm{Ly}_{51} 1^{-} \mathrm{MHCII}{ }^{\text {high }} \mathrm{CD} 80^{\text {high }}$ and sorted into RPMI media (Sigma) containing 10\% FSC and 1\% Penicillin/Streptomycin (Gibco). Cells were then cultured in a 96-flat-well plate in $200 \mu \mathrm{L}$ of $10 \%$ FSC RPMI with Penicillin/ Streptomycin in the presence of Endotoxin-free TLR ligands (InvivoGen) or recombinant mouse cytokines: TLR9 ligand-CpG ODN (ODN 1826) (5 $\mu \mathrm{M})$ ), TLR4 ligand-LPS $(1 \mu \mathrm{g} / \mathrm{ml})$, Il-1 $13(10 \mathrm{ng} / \mathrm{ml})$, Il-33 $(10 \mathrm{ng} / \mathrm{ml})$ (both ImmunoTools) and Il-18 $(10 \mathrm{ng} / \mathrm{ml})$ (Biolegend). After $24 \mathrm{~h}$, the supernatant was removed and the cells were resuspended in RNA-lysis buffer. Subsequently, RNA isolation was performed.

In vivo TLR stimulation. For intrathymic injections, mice were anesthetized by i.p. injection of Zoletil (Tiletamine $(50 \mathrm{mg} / \mathrm{ml})$ and Zolazepam $(50 \mathrm{mg} / \mathrm{ml})$, Virbac) dissolved in PBS at a dose of $50 \mathrm{mg} / \mathrm{kg}$ and $10-20 \mu \mathrm{l}$ of $500 \mu \mathrm{M} \mathrm{CpG} \mathrm{ODN} \mathrm{(ODN}$ 1826, InvivoGen) or PBS was injected using an insulin syringe (29G) directly into the first intercostal space from the manubrium $\sim 2 \mathrm{~mm}$ left of the sternum and 4 $\mathrm{mm}$ in depth. The angle of injection was from 25 to $30^{\circ}$ relative to the sternum ${ }^{77}$. For systemic TLR9 stimulation, mice were injected by CpG ODN (ODN 1826, InvivoGen) $(500 \mu \mathrm{M})$ or PBS at day 0 and day 1 into the peritoneum. Mice were then maintained under SPF conditions and euthanized at the indicated time point of an experiment.

\section{Immunofluorescent analysis of thymic cryosections. The thymus was fixed} overnight in $4 \%$ paraformaldehyde (Sigma) at $4{ }^{\circ} \mathrm{C}$, washed three times in PBS, incubated overnight in $30 \%$ sucrose at $4^{\circ} \mathrm{C}$, and finally embedded in OCT compound (VWR). Cryoblocks were cut at $8 \mu \mathrm{m}$ and blocked with PBS containing 5\% BSA (w/v) and $0.1 \%$ Triton X-100 for 1 hour at room temperature. Samples were incubated overnight at $4{ }^{\circ} \mathrm{C}$ with the following primary antibodies: anti-keratin 14, Sirpa, and CD11c-biotin (Fig. 3d) or anti-Involucrin and anti-EpCAM-APC (Supplementary Fig. 3b). The samples were stained with secondary reagents, Goat anti-rat AF-568, goat anti-rabbit AF-647 and streptavidin FITC or goat anti-rabbit AF-488 for one hour at RT. Sections stained only with secondary reagents were used as negative controls. 4',6-diamino-2-phenylindole (DAPI) was used to visualize cell nuclei. Stained sections were mounted in Vectashield medium (Vector Laboratories) and imaged using a Dragonfly 503 (Andor) - spinning disk confocal microscope with the immersion objective HC PL APO $20 \times / 0.75$. A complete list of staining reagents can be found in Supplementary Data 6. Z-stacks were composed using ImageJ and

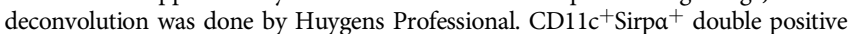
cells were counted in multiple $300 \mu \mathrm{mx} 300 \mu \mathrm{m}$ areas in keratin-14 rich (medulla) and keratin-14 negative (cortex) region. Counting was done as a blind experiment by three different investigators. Involucrin ${ }^{+} \mathrm{EpCAM}^{+}$double positive cells were counted as number of cells per thymic medullary region (determined by DAPI staining).

Gene expression analysis by qRT-PCR. Total RNA from FACS-sorted cells was extracted using an RNeasy Plus Micro Kit (Qiagen) and reverse transcribed using RevertAid (ThermoFisher) transcriptase and random hexamers (ThermoFisher). Quantitative RT PCR (qRT PCR) was performed using the LightCycler 480 SYBR Green I Master mix (Roche) on a LightCycler 480 II (Roche). Each sample was tested in duplicate. Threshold cycles were calculated using LightCycler 480 1.5 software. Gene expression was calculated by the relative quantification model ${ }^{78}$ using the mRNA levels of the housekeeping gene, Casc3, as a control. Primers were designed using Primer-BLAST (NCBI, NIH). Primers sequences are listed in Supplementary Data 6.

Bone marrow chimera generation. Bone marrow cells were isolated from the femur and tibia of Ly5.1 mice $\left(\mathrm{CD} 45.1^{+}\right)$and subsequently depleted of erythrocytes using ACK lysis buffer. Recipient mice (Foxn1 ${ }^{\text {Cre }}$ ROSA26 TdTOMATO, CD45.2 ${ }^{+}$) were irradiated with $6 \mathrm{~Gy}$ and reconstituted with $2 \times 10^{6}$ donor BM cells. These mice were maintained on water supplemented with gentamycin $(1 \mathrm{mg} / \mathrm{ml})$ for 10 days. Three weeks after irradiation, the frequency of blood cell reconstitution was measured by FACS using anti-CD45.1 and CD45.2 antibodies. If the reconstitution was higher than $80 \%$, mice were euthanized 6 weeks after transfer and subjected to further analysis.

RNA-sequencing and analysis. mTECs were sorted according to the protocol described above and RNA was extracted using a RNeasy Plus Micro Kit (Qiagen). cDNA synthesis, ligation of sequencing adaptors and indexes, ribosomal cDNA depletion, final PCR amplification and product purification were prepared with a SMARTer $^{\oplus}$ Stranded Total RNA-Seq - Pico Input Mammalian library preparation kit v2 (Takara). Library size distribution was evaluated on a Agilent 2100 Bioanalyzer using the High Sensitivity DNA Kit (Agilent). Libraries were sequenced on a Illumina NextSeq ${ }^{\oplus} 500$ instrument using a 76 bp single-end high-output configuration resulting in $\sim 30$ million reads per sample. Read quality was assessed by FastQC (0.11.9). Subsequent read processing including removing sequencing adaptors (Trim Galore!, version 0.4.5), mapping to the reference genome (GRCm38 (Ensembl assembly version 91)) with HISAT2 (2.1.0), and quantifying expression at the genetic level (featureCounts) was done via the SciLifeLab/NGIRNAseq pipeline [https://github.com/SciLifeLab/NGI-RNAseq]. Final per gene read counts served as an input for differential expression analysis using a DESeq2 R Bioconductor (3.10). Prior to this analysis, genes that were not expressed in at least two samples were discarded. Genes exhibiting a minimal absolute log2-fold change value of 1 and a statistical significance (adjusted $p$-value $<0.05$ ) between conditions were considered as differentially expressed for subsequent interpretation and visualization. All figures (volcano plots, etc.) were generated using basic R graphical functions. The raw sequencing data were deposited at the ArrayExpress database under accession numbers E-MTAB-8024 (for Fig. 2a, b) and E-MTAB-8025 (for Fig. 2d, e).

Single-cell RNA sequencing. DCs were sorted from Foxn $1{ }^{\text {Cre }}$ ROSA26 6 TdTOMATO as $\mathrm{Gr}-1^{-} \mathrm{CD} 11 \mathrm{c}^{+} \mathrm{TdTOM}^{+}$(described in detail in Supplementary Fig. 3a and Fig. 4c). Two independent samples (Sample 1 and 2) were used for further analysis. A single-cell library was prepared by Illumina/Bio-Rad single-cell RNA-seq system with a SureCell WTA 3' Library Prep Kit according to the manufacturer's instructions. Total cell concentration and viability was ascertained using a TC20 Automated Cell Counter (Bio-Rad). A ddSEQ Single-Cell Isolator (Bio-Rad) was used to co-encapsulate single cells with barcodes and enzyme solutions for cDNA synthesis. Nextera SureCell transposome solution was used for cDNA fragmentation and ligation of sequencing indexes, followed by PCR amplification and short fragment removal. Finally, library fragment length distribution and concentration were analyzed on a Agilent Bioanalyzer 2100 using a High Sensitivity DNA Kit (Agilent). The resulting libraries were sequenced using a 68/75 paired-end configuration on a Illumina NextSeq ${ }^{\circledast} 500$ instrument resulting in $\sim 73$ million reads per sample.

Single-cell RNA sequencing analysis. The quality of reads was assessed by FastQC. Cell identification was accomplished with cell barcodes and lowexpression cells filtering using UMI-tools ${ }^{79}$. The analysis identified 202 cells in Sample 1 and 218 cells in Sample 2. Reads assigned to the selected cells were mapped to the GRCm38 genome assembly (Ensembl version 91) with HISAT2 (2.1.0). Gene expression was quantified using, featureCounts (2.0.0) after deduplication of per-gene assigned read counts by UMIs with UMI-tools. De-duplicated per-gene read counts were imported into $\mathrm{R}$ for exploration and statistical analysis using a Seurat ${ }^{80}$ package (version 3.0). Counts were normalized according to total expression, multiplied by a scale factor $(10,000)$, and log-transformed. For cell cluster identification and visualization, gene expression values were also scaled according to highly variable genes after controlling for unwanted variation generated by sample identity. Cell clusters were identified based on t-SNE of the first six principal components of PCA using Seurat's method, FindClusters, with a original Louvain algorithm and resolution parameter value of 0.3 . To find cluster marker genes, Seurat's method, FindAllMarkers, along with a likelihood ratio test assuming an underlying negative binomial distribution suitable for UMI datasets was used. Only genes exhibiting a significant (adjusted $p$-value $<0.05$ ) minimal average absolute log2-fold change of 1 between each of the clusters and the rest of the dataset were considered as differentially expressed. For t-SNE expression plots, normalized count data were used. Heatmaps of gene expression per cluster were generated based on gene z-score scaled raw counts. The raw sequencing data was deposited at the ArrayExpress database under accession number E-MTAB-8028.

In vitro antigen presenting assay. For the purpose of antigen presentation assay $\mathrm{CD} 14^{+}$moDCs were gated as $\mathrm{CD} 11 \mathrm{c}^{+} \mathrm{MHCII}^{+} \mathrm{B}_{22} 20^{-} \mathrm{Xcr} 1^{-} \mathrm{Cx} 3 \mathrm{cr} 1^{+} \mathrm{CD} 14^{+}$and FACS sorted from Aire-HCO mice into DMEM high-glucose medium (Sigma) supplemented with $10 \%$ FCS and $1 \%$ Penicillin-Streptomycin (Gibco) and cultivated in a 96 well plate together with the A5 hybridoma cell line (HA-specific CD4 T cell hybridoma cells carrying a GFP-NFAT reporter) at a 1:5 ratio (10 000 of CD14 ${ }^{+}$moDC: 50000 of A5 cells). As a positive control, CD14 ${ }^{+}$moDCs were pulsed with HA peptide (107-119; customized by Thermofisher) at a concentration of $1 \mu \mathrm{g} / \mathrm{ml}$. After $20 \mathrm{~h}$, the level of GFP expression by A5 hybridomas was analyzed by flow cytometry. 
Induction of T cell transfer colitis and histological analysis. FACS-sorted $5 \times 10^{5}$ TCR $\beta^{+}{ }^{+} \mathrm{CD} 4{ }^{+}{ }^{C D} 45 \mathrm{RB}^{\text {high }} \mathrm{CD} 25^{-}$or complete $\mathrm{TCR} \beta^{+} \mathrm{CD} 4^{+}$were transferred by $\mathrm{i}$. p. injection into Rag1 ${ }^{-/-}$recipient mice (5-7 weeks old). The weight of mice was recorded weekly to monitor the progress of colitis. Mice were euthanized 8 weeks after transfer ${ }^{51}$. Spleens and colons of the animals were weighed and the length of the colon was measured. For histological analysis PBS washed colons were fixed in $4 \%$ paraformaldehyde (Sigma) and embedded into paraffin. Tissue sections were cut into $5 \mu \mathrm{m}$ thin slices, deparaffinized, and stained with hematoxylin and eosin (H\&E).

In vitro Tregs suppression assay. BM-derived DCs (BMDCs) were prepared as follows. BM cells were flushed from femur and tibia of WT C57BL/6 mice and cultured in RPMI media (Sigma) containing $10 \%$ FSC and $1 \%$ Penicillin/Streptomycin (Gibco) supplemented with GM-CSF $(5 \mathrm{ng} / \mathrm{ml})$. Fresh media containing GMCSF was added at day 3 and 5 of cultivation. After 7 days, BMDCs was pulsed with OVA cognate peptide 323-339 (irrelevant OVA 257-264 peptide was used as control) (InvivoGen) at a concentration of $1 \mu \mathrm{g} / \mathrm{ml}$ and co-cultivated with OVA-specific OT-II T cells and Tregs (10 000 BMDCs: 50000 OT-II T cells: 50000 Tregs). OT-II T cells were isolated from OT-II ${ }^{+} \mathrm{Rag}^{-1-}$ mice as MACS-enriched $\mathrm{CD} 4^{+} \mathrm{T}$ cells $\left(\mathrm{CD} 4^{+} \mathrm{T}\right.$ Cell Isolation Kit, Miltenyi biotec). $\mathrm{CD}^{+}$conventional $\mathrm{T}$ cells (Tconv) were used as a negative control. Tregs were isolated from LNs (pLN and mLN) of WT (MyD88 $\left.8^{\mathrm{f} / \mathrm{fl}}\right)$ and $\mathrm{MyD} 88^{\triangle \mathrm{TECs}}$ mice using subsequent Auto-MACS (Miltenyi biotec) procedure. CD4-enriched $\mathrm{T}$ cells $\left(\mathrm{CD} 4^{+} \mathrm{T}\right.$ Cell Isolation Kit, Miltenyi biotec) were stained by anti-CD25 biotin conjugated antibody and $\mathrm{CD} 4{ }^{+} \mathrm{CD} 25^{+}$Tregs were isolated using Anti-Biotin MicroBeads (Miltenyi biotec). Tconv cells were prepared using AutoMACS as $\mathrm{CD} 4{ }^{+} \mathrm{CD} 25^{-}$cells. After 3 days of co-cultivation, cells were stained with anti-V $\beta 5$ and anti-Va2 antibodies to distinguish OT-II ${ }^{+} \mathrm{T}$ cells. Proliferation was measured by FACS using CPD670 staining.

In vivo model of autoimmune diabetes. $\mathrm{Cd} 3 \varepsilon^{-/}$RIP-OVA mice (6-8 weeks old) were intravenously injected by MACS enriched $\mathrm{CD}^{+} \mathrm{T}$ cells $\left(5 \times 10^{5}\right.$ cells per mouse) isolated from lymph nodes and spleen of Rip-OVA Ly5.1 $\left(\mathrm{CD} 45.1^{+}\right)$mice at day 8. After 7 days (day 1) Cd3 $\varepsilon^{-l-R I P-O V A ~ m i c e ~ w e r e ~ i n t r a v e n o u s l y ~ i n j e c t e d, ~}$ FACS sorted $\mathrm{CD} 4{ }^{+} \mathrm{CD} 25^{+}$Tregs were isolated from LNs (mLN and pLN) of WT $\left(\mathrm{MyD} 88^{\mathrm{fl} / \mathrm{fl}}\right), \mathrm{MyD} 88^{\Delta \mathrm{TECs}}$ mice $\left(3 \times 10^{5}\right.$ cells per mouse), OT-I (OT-I+Rag2 ${ }^{-/-}$, 100 cells per mouse), and OT-II cells (OT-II ${ }^{+} \mathrm{Rag}^{-/-}, 1 \times 10^{4}$ cells per mouse). BMDCs (generated as described previously, 10 days of culture, media refreshment at day 4 and 7) were pulsed with OVA peptides (OVA 257-264, $2 \mathrm{mM}$ and OVA $323-339,100 \mu \mathrm{M}$, InvivoGen) in the presence of LPS (100 $\mu \mathrm{g} / \mathrm{ml}$, InvivoGen) for $3 \mathrm{~h}$. In all, $1 \times 10^{6}$ of antigen-stimulated DCs were used for injection (at day 0 ). Glucose levels were monitored on a daily basis (between day 5 and 14) using test strips (Diabur-Test 5000, Roche or GLUKOPHAN, Erba Lachema, Czech Republic). The animal was considered to have developed autoimmunity when the concentration of glucose in the urine reached $\geq 10 \mathrm{mmol} / \mathrm{l}$. At day 14 , mice were euthanized and the frequency of splenic KLGR $1^{+} \mathrm{OT}-1 \mathrm{~T}$ cells was measured by flow cytometry.

Statistical analysis. The statistical tests used to analyze the data are indicated in figure legends. Graph construction and statistical analysis were performed using Prism 5.04 software (GraphPad). Statistical analysis of RNAseq and scRNAseq data is indicated in the corresponding method section.

Reporting summary. Further information on research design is available in the Nature Research Reporting Summary linked to this article.

\section{Data availability}

The authors declare that all data supporting the findings of this study are available within the article and its supplementary information files or from the corresponding author upon reasonable request. The source data underlying Fig. 1c, f, 2c, f, g, 3a-c, e, 4d, f, 5d, f, g, 6a, c, e-i, 7b, d-h and Supplementary Figs. 2b-d, 3a, b, d, e, 4c, 5e, f, 6c, e, h, 7a-d, f, h and $8 b, c$, e are provided as a Source Data file. The raw RNA sequencing data are deposited at the ArrayExpress database [https://www.ebi.ac.uk/arrayexpress/] under accession numbers E-MTAB-8024 (Fig. 2a, b), E-MTAB-8025 (Fig. 2d, e) and E-MTAB8028 (Fig. 5a-c).

Received: 2 July 2019; Accepted: 12 April 2020;

Published online: 12 May 2020

\section{References}

1. Klein, L., Kyewski, B., Allen, P. M. \& Hogquist, K. A. Positive and negative selection of the $\mathrm{T}$ cell repertoire: what thymocytes see (and don't see). Nat. Rev. Immunol. 14, 377-391 (2014).

2. Anderson, M. S. et al. Projection of an immunological self shadow within the thymus by the aire protein. Science 298, 1395-1401 (2002).
3. Liston, A., Lesage, S., Wilson, J., Peltonen, L. \& Goodnow, C. C. Aire regulates negative selection of organ-specific T cells. Nat. Immunol. 4, 350-354 (2003)

4. Aschenbrenner, K. et al. Selection of Foxp3+ regulatory T cells specific for self antigen expressed and presented by Aire+ medullary thymic epithelial cells. Nat. Immunol. 8, 351-358 (2007).

5. Malchow, S. et al. Aire-dependent thymic development of tumor-associated regulatory T cells. Science 339, 1219-1224 (2013).

6. Perry, J. S. et al. Distinct contributions of Aire and antigen-presenting-cell subsets to the generation of self-tolerance in the thymus. Immunity $\mathbf{4 1}$, 414-426 (2014).

7. Leventhal, D. S. et al. Dendritic cells coordinate the development and homeostasis of organ-specific regulatory T cells. Immunity 44, 847-859 (2016).

8. Gallegos, A. M. \& Bevan, M. J. Central tolerance to tissue-specific antigens mediated by direct and indirect antigen presentation. J. Exp. Med. 200, 1039-1049 (2004).

9. Koble, C. \& Kyewski, B. The thymic medulla: a unique microenvironment for intercellular self-antigen transfer. J. Exp. Med. 206, 1505-1513 (2009)

10. Perry, J. S. A. et al. Transfer of cell-surface antigens by scavenger receptor $\mathrm{CD} 36$ promotes thymic regulatory $\mathrm{t}$ cell receptor repertoire development and allo-tolerance. Immunity 48, 1271 (2018).

11. Lancaster, J. N. et al. Live-cell imaging reveals the relative contributions of antigen-presenting cell subsets to thymic central tolerance. Nat. Commun. 10, 2220 (2019)

12. Li, J., Park, J., Foss, D. \& Goldschneider, I. Thymus-homing peripheral dendritic cells constitute two of the three major subsets of dendritic cells in the steady-state thymus. J. Exp. Med. 206, 607-622 (2009).

13. Guilliams, M. et al. Dendritic cells, monocytes and macrophages: a unified nomenclature based on ontogeny. Nat. Rev. Immunol. 14, 571-578 (2014).

14. Hadeiba, H. et al. Plasmacytoid dendritic cells transport peripheral antigens to the thymus to promote central tolerance. Immunity 36, 438-450 (2012).

15. Bonasio, R. et al. Clonal deletion of thymocytes by circulating dendritic cells homing to the thymus. Nat. Immunol. 7, 1092-1100 (2006).

16. Kroger, C. J., Spidale, N. A., Wang, B. \& Tisch, R. Thymic dendritic cell subsets display distinct efficiencies and mechanisms of intercellular MHC transfer. J. Immunol. 198, 249-256 (2017).

17. Leventhal, D. S. et al. Dendritic cells coordinate the development and homeostasis of organ-specific regulatory T cells. Immunity 44, 847-859 (2016).

18. Lei, Y. et al. Aire-dependent production of XCL1 mediates medullary accumulation of thymic dendritic cells and contributes to regulatory $\mathrm{T}$ cell development. J. Exp. Med. 208, 383-394 (2011).

19. Baba, T., Nakamoto, Y. \& Mukaida, N. Crucial contribution of thymic Sirp alpha + conventional dendritic cells to central tolerance against bloodborne antigens in a CCR2-dependent manner. J. Immunol. 183, 3053-3063 (2009).

20. $\mathrm{Hu}, \mathrm{Z}$. et al. CCR7 modulates the generation of thymic regulatory $\mathrm{T}$ cells by altering the composition of the thymic dendritic cell compartment. Cell Rep. 21, 168-180 (2017).

21. Kawai, T. \& Akira, S. The role of pattern-recognition receptors in innate immunity: update on Toll-like receptors. Nat. Immunol. 11, 373-384 (2010).

22. Abramson, J. \& Anderson, G. Thymic Epithelial Cells. Annu Rev. Immunol. 35, 85-118 (2017)

23. Haljasorg, U. et al. A highly conserved NF-kappaB-responsive enhancer is critical for thymic expression of Aire in mice. Eur. J. Immunol. 45, 3246-3256 (2015).

24. LaFlam, T. N. et al. Identification of a novel cis-regulatory element essential for immune tolerance. J. Exp. Med. 212, 1993-2002 (2015).

25. Bernasconi, P. et al. Increased toll-like receptor 4 expression in thymus of myasthenic patients with thymitis and thymic involution. Am. J. Pathol. 167, 129-139 (2005).

26. Cavalcante, P. et al. Toll-like receptors 7 and 9 in myasthenia gravis thymus: amplifiers of autoimmunity? Ann. N. Y Acad. Sci. 1413, 11-24 (2018).

27. Huang, H. B. et al. TLR4 is constitutively expressed in chick thymic epithelial cells. Vet. Immunol. Immunopathol. 158, 182-188 (2014).

28. Tian, J. et al. Toll-like receptor 9-dependent activation by DNA-containing immune complexes is mediated by HMGB1 and RAGE. Nat. Immunol. 8 , 487-496 (2007).

29. Gordon, J. et al. Specific expression of lacZ and cre recombinase in fetal thymic epithelial cells by multiplex gene targeting at the Foxn1 locus. BMC Dev. Biol. 7, 69 (2007).

30. Hou, B., Reizis, B. \& DeFranco, A. L. Toll-like receptors activate innate and adaptive immunity by using dendritic cell-intrinsic and -extrinsic mechanisms. Immunity 29, 272-282 (2008).

31. Sansom, S. N. et al. Population and single-cell genomics reveal the Aire dependency, relief from Polycomb silencing, and distribution of self-antigen expression in thymic epithelia. Genome Res. 24, 1918-1931 (2014). 
32. Griffith, J. W., Sokol, C. L. \& Luster, A. D. Chemokines and chemokine receptors: positioning cells for host defense and immunity. Annu Rev. Immunol. 32, 659-702 (2014).

33. Vigne, S. et al. IL-36R ligands are potent regulators of dendritic and T cells. Blood 118, 5813-5823 (2011).

34. Becher, B., Tugues, S. \& Greter, M. GM-CSF: from growth factor to central mediator of tissue inflammation. Immunity 45, 963-973 (2016).

35. Zlotoff, D. A. et al. CCR7 and CCR9 together recruit hematopoietic progenitors to the adult thymus. Blood 115, 1897-1905 (2010).

36. Dyer, D. P. et al. Chemokine receptor redundancy and specificity are context dependent. Immunity 50, 378-389.e375 (2019).

37. Belperio, J. A. et al. Critical role for CXCR2 and CXCR2 ligands during the pathogenesis of ventilator-induced lung injury. J. Clin. Invest. 110, 1703-1716 (2002).

38. Fields, J. K., Günther, S. \& Sundberg, E. J. Structural Basis of IL-1 Family Cytokine Signaling. Front Immunol. 10, 1412 (2019).

39. Eckhart, L., Lippens, S., Tschachler, E. \& Declercq, W. Cell death by cornification. Biochim Biophys. Acta 1833, 3471-3480 (2013).

40. Miller, C. N. et al. Thymic tuft cells promote an IL-4-enriched medulla and shape thymocyte development. Nature 559, 627-631 (2018).

41. Bornstein, C. et al. Single-cell mapping of the thymic stroma identifies IL-25producing tuft epithelial cells. Nature 559, 622-626 (2018).

42. Wang, J. et al. Hassall's corpuscles with cellular-senescence features maintain IFNa production through neutrophils and $\mathrm{pDC}$ activation in the thymus. Int Immunol. 31, 127-139 (2019).

43. Kolodziejczyk, A. A., Kim, J. K., Svensson, V., Marioni, J. C. \& Teichmann, S. A. The technology and biology of single-cell RNA sequencing. Mol. Cell 58, 610-620 (2015).

44. Biton, M. et al. T helper cell cytokines modulate intestinal stem cell renewal and differentiation. Cell 175, 1307-1320.e1322 (2018).

45. Ardouin, L. et al. Broad and largely concordant molecular changes characterize tolerogenic and immunogenic dendritic cell maturation in thymus and periphery. Immunity 45, 305-318 (2016).

46. Hettinger, J. et al. Origin of monocytes and macrophages in a committed progenitor. Nat. Immunol. 14, 821-830 (2013).

47. Hinterberger, M. et al. Autonomous role of medullary thymic epithelial cells in central CD4(+) T cell tolerance. Nat. Immunol. 11, 512-519 (2010).

48. McCaughtry, T. M., Wilken, M. S. \& Hogquist, K. A. Thymic emigration revisited. J. Exp. Med. 204, 2513-2520 (2007).

49. Thiault, N. et al. Peripheral regulatory $\mathrm{T}$ lymphocytes recirculating to the thymus suppress the development of their precursors. Nat. Immunol. 16, 628-634 (2015).

50. Owen, D. L. et al. Thymic regulatory T cells arise via two distinct developmental programs. Nat. Immunol. 20, 195-205 (2019).

51. Mottet, C., Uhlig, H. H. \& Powrie, F. Cutting edge: cure of colitis by CD4 +CD25+ regulatory T cells. J. Immunol. 170, 3939-3943 (2003).

52. Drobek, A. et al. Strong homeostatic TCR signals induce formation of selftolerant virtual memory CD8 T cells. EMBO J 37, e98518 (2018).

53. Gray, D. H., Gavanescu, I., Benoist, C. \& Mathis, D. Danger-free autoimmune disease in Aire-deficient mice. Proc. Natl Acad. Sci. USA 104, 18193-18198 (2007).

54. Yano, M. et al. Aire controls the differentiation program of thymic epithelial cells in the medulla for the establishment of self-tolerance. J. Exp. Med. 205, 2827-2838 (2008).

55. White, A. J. et al. Lymphotoxin signals from positively selected thymocytes regulate the terminal differentiation of medullary thymic epithelial cells. $J$. Immunol. 185, 4769-4776 (2010).

56. Lancaster, J. N., Li, Y. \& Ehrlich, L. I. R. Chemokine-mediated choreography of thymocyte development and selection. Trends Immunol. 39, 86-98 (2018).

57. Klein, L. Dead man walking: how thymocytes scan the medulla. Nat. Immunol. 10, 809-811 (2009).

58. Yamano, T. et al. Thymic B cells are licensed to present self antigens for Central T cell tolerance induction. Immunity 42, 1048-1061 (2015).

59. Ohnmacht, C. et al. Constitutive ablation of dendritic cells breaks selftolerance of CD4 $\mathrm{T}$ cells and results in spontaneous fatal autoimmunity. J. Exp. Med. 206, 549-559 (2009).

60. Román, E., Shino, H., Qin, F. X. \& Liu, Y. J. Cutting edge: Hematopoieticderived APCs select regulatory T cells in thymus. J. Immunol. 185, 3819-3823 (2010).

61. Salomon, B. et al. B7/CD28 costimulation is essential for the homeostasis of the CD4+CD25+ immunoregulatory $\mathrm{T}$ cells that control autoimmune diabetes. Immunity 12, 431-440 (2000).

62. Coquet, J. M. et al. Epithelial and dendritic cells in the thymic medulla promote CD4+Foxp3+ regulatory T cell development via the CD27-CD70 pathway. J. Exp. Med 210, 715-728 (2013).

63. Proietto, A. I. et al. Dendritic cells in the thymus contribute to T-regulatory cell induction. Proc. Natl Acad. Sci. USA 105, 19869-19874 (2008).
64. Cowan, J. E. et al. Aire controls the recirculation of murine Foxp3. Eur. J. Immunol. 48, 844-854 (2018).

65. Mombaerts, P. et al. RAG-1-deficient mice have no mature B and T lymphocytes. Cell 68, 869-877 (1992).

66. Janowska-Wieczorek, A. et al. Platelet-derived microparticles bind to hematopoietic stem/progenitor cells and enhance their engraftment. Blood $\mathbf{9 8}$, 3143-3149 (2001).

67. Liu, L. et al. Functional defect of peripheral neutrophils in mice with induced deletion of CXCR2. Genesis 51, 587-595 (2013).

68. Hashimoto, K., Joshi, S. K. \& Koni, P. A. A conditional null allele of the major histocompatibility IA-beta chain gene. Genesis 32, 152-153 (2002).

69. Caton, M. L., Smith-Raska, M. R. \& Reizis, B. Notch-RBP-J signaling controls the homeostasis of CD8- dendritic cells in the spleen. J. Exp. Med 204, 1653-1664 (2007)

70. Madisen, L. et al. A robust and high-throughput Cre reporting and characterization system for the whole mouse brain. Nat. Neurosci. 13, 133-140 (2010).

71. de Boer, J. et al. Transgenic mice with hematopoietic and lymphoid specific expression of Cre. Eur. J. Immunol. 33, 314-325 (2003).

72. Sommers, C. L. et al. Function of CD3 epsilon-mediated signals in T cell development. J. Exp. Med. 192, 913-919 (2000).

73. Kurts, C., Miller, J. F., Subramaniam, R. M., Carbone, F. R. \& Heath, W. R. Major histocompatibility complex class I-restricted cross-presentation is biased towards high dose antigens and those released during cellular destruction. J. Exp. Med. 188, 409-414 (1998).

74. Palmer, E., Drobek, A. \& Stepanek, O. Opposing effects of actin signaling and LFA-1 on establishing the affinity threshold for inducing effector T cell responses in mice. Eur. J. Immunol. 46, 1887-1901 (2016).

75. Barnden, M. J., Allison, J., Heath, W. R. \& Carbone, F. R. Defective TCR expression in transgenic mice constructed using cDNA-based alpha- and betachain genes under the control of heterologous regulatory elements. Immunol. Cell Biol. 76, 34-40 (1998).

76. Dobeš, J. et al. A novel conditional Aire allele enables cell-specific ablation of the immune tolerance regulator Aire. Eur. J. Immunol. 48, 546-548 (2018).

77. Liu, L. L. et al. A simplified intrathymic injection technique for mice. Biotech Histochem. 87, 140-147 (2012).

78. Pfaffl, M. W. A new mathematical model for relative quantification in realtime RT-PCR. Nucleic Acids Res. 29, e45 (2001).

79. Smith, T., Heger, A. \& Sudbery, I. UMI-tools: modeling sequencing errors in Unique Molecular Identifiers to improve quantification accuracy. Genome Res. 27, 491-499 (2017).

80. Butler, A., Hoffman, P., Smibert, P., Papalexi, E. \& Satija, R. Integrating singlecell transcriptomic data across different conditions, technologies, and species. Nat. Biotechnol. 36, 411-420 (2018).

\section{Acknowledgements}

We would like to thank Z. Cimburek and M. Śíma for FACS sorting, Š. Kocourková for preparation of cDNA libraries for RNA sequencing experiments and A. Malinová and I. Novotný for technical assistance with microscopic experiments. V. Kořínek for providing the ROSA $26^{\text {TdTOMATO }}$ and Vav1 ${ }^{\text {Cre }}$ mouse models and T. Brdička for OTII mice. We are indebted to L. Šefc and F. Savvulidi of the Center for Advanced Preclinical Imaging (CAPI) in Prague for their technical assistance with Imaging flow cytometry. We also thank J. Abramson for technical and experimental advice, J. Manning for help with the preparation of the manuscript, and N. Grúnová for graphical design of mice clip arts. This work was supported by Grant 19-23154S from GACR. M.V. was supported by Grant 154215 from GAUK and by Grant ISR-18-31 from the Czech Academy of Sciences. T.B and I.Š. were partially supported by Grant RVO: 68378050-KAV-NPUI. O.S. was supported by SNSF (Promys, IZ11Z0_166538). R.S. was supported by grants LM2015040 and LQ1604 by MEYS) and OP RDI CZ.1.05/1.1.00/02.0109 and CZ.1.05/2.1.00/19.0395 from the MEYS and European Regional Development Fund. L.K. was supported by the European Research Council (ERC-2016-ADG 742290) and the Deutsche Forschungsgemeinschaft (SFB 1054).

\section{Author contributions}

M.V. co-designed and conducted the majority of the experiments and wrote the manuscript. T.B., J.D., and J.B. performed some experiments and provided technical help I.Š. performed microscopic experiments. A.Č., M.D., and A.A. provided technical support for the work. O.T. and O.Š. performed the experiments using mouse diabetic model. M.K. and V.B. performed RNA sequencing. J.K. analyzed RNAseq and scRNAseq data R.S. and L.K provided technical and experimental help, mice and material. D.F. designed experiments, supervised research, and edited the paper. 


\section{Competing interests}

The authors declare no competing interests.

\section{Additional information}

Supplementary information is available for this paper at https://doi.org/10.1038/s41467020-16081-3

Correspondence and requests for materials should be addressed to D.F.

Reprints and permission information is available at http://www.nature.com/reprints

Publisher's note Springer Nature remains neutral with regard to jurisdictional claims in published maps and institutional affiliations. (c) (i) Open Access This article is licensed under a Creative Commons Attribution 4.0 International License, which permits use, sharing, adaptation, distribution and reproduction in any medium or format, as long as you give appropriate credit to the original author(s) and the source, provide a link to the Creative Commons license, and indicate if changes were made. The images or other third party material in this article are included in the article's Creative Commons license, unless indicated otherwise in a credit line to the material. If material is not included in the article's Creative Commons license and your intended use is not permitted by statutory regulation or exceeds the permitted use, you will need to obtain permission directly from the copyright holder. To view a copy of this license, visit http://creativecommons.org/ licenses/by/4.0/.

(C) The Author(s) 2020 